\title{
LOS PARLAMENTARIOS CENTROAMERICANOS Y LAS INSTITUCIONES POLÍTICAS: PERCEPCIONES Y RELACIONES EN LA CONSTRUCCIÓN DEMOCRÁTICA
}

\author{
Juany Guzmán León*
}

\section{INTRODUCCIÓN}

Los años noventa se constituyen para Centroamérica en una redefinición de los parlamentos como el escenario por excelencia del debate público. Adquiere un notable protagonismo la discusión sobre la capacidad real en la toma de decisiones, no sólo en relación a su propia función, sino también en el ámbito del conjunto de la institucionalidad política vigente (principalmente en relación al Poder Ejecutivo y las Fuerzas Armadas).

En efecto, contradiciendo la historia reciente, caracterizada por la preeminencia de una tradición política autoritaria, en la que el parlamento formalmente no se había destruido, pero cuya labor estaba fuertemente subordinada a otras instancias de toma de decisiones públicas; hoy, inscribiéndose en el contexto de los procesos de democratización que experimenta la región, los parlamentos están replanteando su papel en la política centroamericana. Esta evidencia justifica el objeto de estudio que motiva no sólo el proyecto de investigación sobre élites parlamentarias, sino también la importancia de conocer las percepciones de los parlamentarios centroamericanos respecto de las demás instituciones políticas' .

El objetivo propuesto es visualizar las percepciones de los parlamentarios respecto del papel de otras instituciones políticas, con las cuales se enfrentan al reto de avanzar en los proceso de consolidación democrática de la región. Por instituciones políticas aquí se entiende al poder ejecutivo, partidos políticos, fuerzas armadas y grupos de interés como sindicatos, cámaras empresariales, organizaciones comunales y religiosas. También se identifican las competencias y funciones establecidas en las constituciones de cada país, a fin de reconocer cómo, a criterio de los parlamentarios, esas dsiposiciones constitucionales están adquiriendo vida en el juego de poder de los sistemas políticos centroamericanos.
Como punto de partida, se considera necesario tomar en cuenta diversos aspectos para analizar las percepciones y relaciones diputados-instituciones en el proceso de consolidación democrática. El primero de ellos tiene que ver con el grado de consolidación del sistema político en cada uno de los países objeto de estudio. Ello remite a los márgenes de legitimidad y reconocimiento de los interlocutores sociales, como interlocutores "válidos". El segundo elemento refiere a los mecanismos de resolución pacífica de conflictos que han adquirido fuerza en la historia reciente de la región, y que en unos casos se traduce en una "nueva manera de hacer política". Los parlamentos han pasado a ser los campos de negociación entre los mismos actores políticos que se enfrentaban en los campos de batalla durante la guerra de décadas anteriores.

Un tercer elemento que caracteriza las acciones de los parlamentarios y sus percepciones respecto de los otros actores sociales, podría denominarse el "peso de la inmediatez". La urgencia de resolver problemas clave de los procesos de transición democrática, de crisis fiscal, de estrechamiento de los márgenes de maniobra de los actores políticos nacionales y la redefinición de las alianzas, como consecuencias del final de la guerra y la inserción en el juego democrático, entre otros; parecen revelar nuevas relaciones entre los poderes del Estado y con otras instancias como son las Fuerzas Armadas y otras organizaciones sociales. Todo lo cual converge e influye en la dinámica de

Universidad de Costa Rica

1. Este artículo se inscribe en el marco del Proyecto de Investigación: Elites parlamentarias en América Latina coordinado por el Dr. Manuel Alcántara Sáez, Catedrático de la Universidad de Salamanca. La información básica que sustenta esta ponencia refiere a los resultados de la encuesta que se ha realizando en toda América Latina, a los congresistas del subcontinente. Para este trabajo se han tomado en cuenta los datos obtenidos de la encuesta sometida a consideración en Costa Rica (52 de 57), El Salvador (46 de 84), Honduras (67 de 128) y Nicaragua (41 de 92), para un porcentaje promedio del 57,06 del total de parlamentarios de estos países. 
poder y de toma de decisiones que es por excelencia el Parlamento.

Las relaciones Asamblea Legislativa-Poder Ejecutivo, Asamblea Legislativa-Poder Judicial, Asamblea Legislativa-Fuerzas Armadas y Asamblea Legislativa-organizaciones sociales, adquiere para Centroamérica una particular relevancia, porque da cuenta del proceso de reconstrucción de los sistemas políticos en los que los espacios institucionales de participación y representación, eran utilizados como instrumentos de unas "democracias de fachada" 2; para constituirse en instancias legítimas de construcción democrática en las que los actores se reconocen mutuamente como protagonistas de una opción por la resolución de los conflictos en el marco de Estados democráticos de Derecho. La importancia de estos cambios se ve reflejada, además, en el desarrollo constitucional de la década de 1980, que constituye otro de los avabnces que experimentan varios países centroamericanos en el contexto de la transición.

En esta perspectiva, el interés de esta propuesta es, por una parte, abordar las percepciones y valoraciones que los parlamentarios centroamericanos le atribuyen al Ejecutivo, el Poder Judicial y las Fuerzas Armadas en Centroamérica, principalmente; y por otra, iniciar una reflexión sobre la correspondencia que tales valoraciones tienen, con las funciones que las Constituciones de estos países le asignan a las mismas instituciones y poderes del Estado. Aunque la propuesta es un intento de análisis comparativo a nivel regional, debe aclararse que sólo refiere a los países de Costa Rica, El Salvador, Honduras y Nicaragua y que queda pendiente un análisis detallado respecto de otras instituciones políticas y sociales. De cualquier modo, interesa someter a la discusión esta primera aproximación.

\section{EL CONTEXTO DE LA TRANSICIÓN}

El binomio guerra-elecciones es probablemente el más estudiado y abordado por los investigadores centroamericanos y no centroamericanos que han intentado explicar el proceso de transformación de los hechos políticos que ha vivido la región en los últimos quince años. Se ha mencionado el golpe de Estado que derroca el régimen de Carlos Humberto Romero en El Salvador en 1979 y el inicio del gobierno de transición con la incorporción de algunas reformas (reforma agraria en tres etapas, nacionalización bancaria y del comercio de exportación), para identificar un punto de inflexión donde la guerra y las elecciones se juegan una partida hasta hoy aparentemente ganada por las segundas. La firma de los acuerdos de paz en Guatemala, el 29 de diciembre de 1996 puede ser considerada el final de un ciclo que ha mostrado que la opción electoral debe desbordarse a sí misma, y llevar a procesos de negociación y diálogo entre los actores políticos y sociales, que hagan del juego electoral sólo un mecanismo de garantía de transferencia del poder en condiciones de libertad entre interlocutores válidoss.
Este proceso da cuenta de que el viraje en Centroamérica hacia una opción por la resolución pacífica de los conflictos, se torna en el desafío por la irreversibilidad en condiciones de extrema vulnerabilidad. Pero sin ninguna duda El Salvador, Nicaragua y Guatemala que enfrentan durante las décadas de 1970 y 1980 los acontecimientos que derivaron en la lucha armada y la violencia, son quienes inauguran también ese proceso de cambio que reorienta la dinámica política de toda la región centroamericana.

No es del caso aquí analizar las razones que se aducen para explicar esa sucesión de cambios. De cualquier manera, hay que rescatar la importancia que se le ha dado a la convocatoria a elecciones y la legalización/consensualización del poder como una "hija bastarda" de los procesos revolucionarios que llegaron a ser opción de poder sobretodo en el primer lustro de los años ochenta ${ }^{3}$. Pero por supuesto que eso no explica la crisis de legitimidad de los gobiernos militares y que hace crisis en las discrepancias que se evidencian en las fuerzas armadas en El Salvador, Nicaragua y Honduras. Paz García en Honduras, la destitución del General Romero en El Salvador y la expulsión de Romeo Lucas, son ejemplos que revelan un aspecto central en la transición política en Centroamérica y que tal vez no ha sido lo suficientemente estudiado: el repliegue de los militares abrió el camino a los gobiernos civiles. Ello no implica desde luego subestimar el contexto internacional (una política exterior norteamericana que promueven las elecciones como garantes de democracia política, militares cuestionados y ola democratizadora en América del Sur, transformaciones de gran envergadura en Europa central y del este), que facilita y encamina la política de los países centroamericanos hacia la instauración de mecanismos que fueran orientando a los actores en pugna, hacia el juego de poder mediado por las contiendas electorales.

Esto es central para ubicar la importancia que adquieren los parlamentos, que saltan al espacio público como los escenarios por excelencia del "encuentro" de enemigos políticos, antes enfrentados en los campos de batalla, para construir el arma cuya tecnología no tiene la sofisticación pero tampoco la precisión de las armas bélicas. Tal es el caso del diálogo y la negociación. La construcción democrática en Centroamérica pasa entonces por cambios sustantivos en las instancias de toma de decisiones y en los mecanismos de resolución de conflictos. El reconocimiento de los interlocutores políticos, a su vez, supone un proceso mediante el cual no es automático el reconocimiento de estos como "válidos". Esa validez, para el caso de quienes ocupan los puestos titulares de los poderes del Estado, debe cruzar el puente del sufragio: hay que ser electo — sin fraude—, para ser válido. Sin embargo, como se indica en adelante, la consolidación democrática; esto es la consolidación de la validez de esta "nueva manera de hacer política", resulta a la

2. Véase: Mario Solórzano. Democracia y autoritarismo en Centroamérica. EDUCA. Guatemala, 1983; Edelberto Torres Rivas: Centroamérica: la democracia posible. EDUCA-FLACSO. San José, 1988.

3. Carlos Figueroa Ibarra. "Centroamérica, entre la crisis y la esperanza”. En Torres-Rivas, E. (editor). Historia General de Centroamérica. Tomo VI. Segunda edición. FLACSO. San José, 1994. 
larga insuficiente si ésta se reduce a cruzar el puente del sufragio. Otras exigencias del quehacer político van permeando la gestión pública de los políticos electos y en las que la capacidad de respuesta acerca o aleja la democratización del sistema político y de la sociedad en su conjunto.

Ello explica la importancia de analizar las percepciones de los congresistas respecto del papel que desempeñan las demás instituciones políticas en la construcción democrática y su corrrespondencia con la función que la Constitución les atribuye. Queda por hacer en este momento la aclaración de que para los efectos de esta propuesta, serán empleados indistintamente los términos parlamentarios, congresistas, diputados, legisladores. Y refiere exclusivamente a quienes ocupan una curul en la Asamblea Legislativa, Asamblea Nacional o Congreso según se le reconozca en cada país, durante su gestión.

\section{LA CONSTITUCIÓN Y LAS INSTITUCIONES POLÍTICAS EN CENTROAMÉRICA}

Con la excepción de Costa Rica, cuya Constitución vigente data de 1949; las de Honduras, El Salvador y Nicaragua rigen a partir de 1982, 1983 y 1987, respectivamente. Esto revela la importancia que el desarrollo constitucional tiene en el contexto de la transición democrática que inician estos países durante la década de 1980. De tal manera que las funciones que los legisladores le atribuyen a las demás instituciones políticas y las que estipula la Constitución, puede mostrar como está el pacto fundamental haciéndose práctica política en estos países.

\section{LA CONSTITUCIÓN Y EL PODER EJECUTIVO EN CENTROAMÉRICA}

\begin{tabular}{||c|}
\hline \multicolumn{1}{|c|}{ COSTA RICA } \\
\hline$-\quad$ LO INTEGRAN: PRESIDENTE Y MINISTROS. \\
$-\quad$ ASAMBLEA DA LICENCIA AL PRESIDENTE \\
\\
PARA SALIR DEL TERRITORIO NACIONAL. \\
EXCEPCIÓN: PAÍSES CENTROAMERICANOS. \\
$-\quad$ CONVOCAR A LA ASAMBLEA A SESIONES \\
ORDINARIAS Y EXTRAORDINARIAS. \\
$-\quad$ DAR A LA ASAMBLEA INFORMES QUE ESTA \\
SOLICITE. \\
$-\quad$ EJERCER EL MANDO SUPREMO DE LA FUER- \\
ZA PÚBLICA. DISPONER DE LA FUERZA \\
PÚBLICA PARA DEFENSA Y SEGURIDAD DEL \\
PAÍS \\
RESPETAR LAS ATRIBUCIONES QUE LA \\
CONSTITUCIÓN LE ATRIBUYE A LOS OTROS \\
PODERES DEL ESTADO.
\end{tabular}

\begin{tabular}{|c|c|}
\hline & HONDURAS \\
\hline- & $\begin{array}{l}\text { LO INTEGRAN: PRESIDENTE Y TRES DESIG- } \\
\text { NADOS A LA PRESIDENCIA. }\end{array}$ \\
\hline - & $\begin{array}{l}\text { ASAMBLEA DA LICENCIA AL PRESIDENTE } \\
\text { PARA SALIR DEL TERRITORIO NACIONAL } \\
\text { POR MÁS DE QUINCE DÍAS. }\end{array}$ \\
\hline - & $\begin{array}{l}\text { PRESIDENTE ES COMANDANTE GENERAL } \\
\text { DE LA FUERZA ARMADA. }\end{array}$ \\
\hline- & $\begin{array}{l}\text { PRESIDENTE DEBE MANTENER INTEGRI- } \\
\text { DAD E INVIOLABILIDAD DEL TERRITORIO. }\end{array}$ \\
\hline- & $\begin{array}{l}\text { ORGANIZAR, CONDUCIR Y MANTENER LA } \\
\text { FUERZA ARMADA. }\end{array}$ \\
\hline
\end{tabular}

\begin{tabular}{|c|c|}
\hline & EL SALVADOR \\
\hline- & $\begin{array}{l}\text { LO INTEGRAN: PRESIDENTE, VICEPRESI- } \\
\text { DENTE, MINISTROS, VICEMINISTROS Y FUN- } \\
\text { CIONARIOS DEPENDIENTES. }\end{array}$ \\
\hline - & $\begin{array}{l}\text { CARGOS DE PRESIDENTE Y VICEPRESIDEN- } \\
\text { TE RENUNCIABLES POR FALTA GRAVE CALI- } \\
\text { FICADA POR LA ASAMBLEA. }\end{array}$ \\
\hline - & $\begin{array}{l}\text { PRESIDENTE ES COMANDANTE GENERAL } \\
\text { DE LA FUERZA ARMADA }\end{array}$ \\
\hline - & $\begin{array}{l}\text { ASAMBLEA DA LICENCIA AL PRESIDENTE } \\
\text { PARA SALIR DEL TERRITORIO NACIONAL. }\end{array}$ \\
\hline - & $\begin{array}{l}\text { DECRETOS, ACUERDOS, ORDENES Y RESO- } \\
\text { LUCIONES DEL EJECUTIVO QUE EXCEDAN } \\
\text { FACULTADES OTORGADAS POR CONSTITU- } \\
\text { CIÓN SON NULOS, AUNQUE SE DEN A } \\
\text { RESERVA DE SOMETERLOS A APROBACIÓN } \\
\text { DE LA ASAMBLEA LEGISLATIVA. }\end{array}$ \\
\hline - & $\begin{array}{l}\text { PRESIDENTE DEBE MANTENER ILESA LA } \\
\text { SOBERANÍA E INTEGRIDAD DEL TERRITORIO. }\end{array}$ \\
\hline - & $\begin{array}{l}\text { DIRIGIR LA GUERRA Y HACER LA PAZ Y SOME- } \\
\text { TER INMEDIATAMENTE EL TRATADO RESPEC- } \\
\text { TIVO A LA RATIFICACION DE LA ASAMBLEA. }\end{array}$ \\
\hline - & $\begin{array}{l}\text { DAR A LA ASAMBLEA INFORMES QUE ESTA } \\
\text { SOLICITE. EXCEPCIÓN: PLANES MILITARES } \\
\text { SECRETOS. }\end{array}$ \\
\hline- & $\begin{array}{l}\text { ORGANIZAR, CONDUCIR Y MANTENER LA } \\
\text { FUERZA ARMADA. }\end{array}$ \\
\hline
\end{tabular}

\section{NICARAGUA}

- LO EJERCE: PRESIDENTE DE LA REPÚBLICA.

- PRESIDENTE ES JEFE DE ESTADO, JEFE DE GOBIERNO Y JEFE SUPREMO DE LAS FUERZAS DE SEGURIDAD.

- ASAMBlea da AUTORIZACIÓN AL PRESIDENTE PARA SALIR DEL TERRITORIO NACIONAL POR MÁS DE UN MES.

- DAR A LA ASAMBLEA INFORMES QUE ESTA SOLICITE. 


\section{LA CONSTITUCIÓN Y LAS FUERZAS ARMADAS EN CENTROAMÉRICA}

\begin{tabular}{||l||}
\hline \multicolumn{1}{||c||}{ COSTA RICA } \\
\hline- PROSCRIBE EL EJERCITO COMO INSTITU- \\
CIÓN PERMANENTE. \\
- SE PODRÁ ORGANIZAR FUERZAS MILITARES \\
SOLO POR CONVENIO CONTINENTAL O \\
PARA LA DEFENSA NACIONAL, SUBORDINA- \\
DAS AL PODER CIVIL, NO PODRÁN DELIBE- \\
RAR, NI HACER MANIFESTACIONES O \\
DECLARACIONES EN FORMA INDIVIDUAL O \\
COLECTIVA. \\
- HABRA LAS FUERZAS DE POLICÍA NECESA- \\
RIAS PARA LA VIGILANCIA Y CONSERVA- \\
CIÓN DEL ORDEN PÚBLICO. \\
- EL PODER EJECUTIVO PONDRÁ A LA \\
ORDEN DE LA ASAMBLEA LEGISLATIVA, LA \\
FUERZA DE POLIĆ́A QUE SOLICITE EL PRE- \\
SIDENTE DE AQUELLA. \\
- EL PRESIDENTE DE LA REPÚBLICA Y LOS \\
MINISTROS DE GOBIERNO DISPONEN DE LA \\
FUERZA PÚBLICA PARA PRESERVAR EL \\
ORDEN, DEFENSA Y SEGURIDAD DEL PAÍS. \\
\hline \hline
\end{tabular}

\begin{tabular}{||l||}
\hline \multicolumn{1}{||c|}{ HONDURAS } \\
\hline- LA INTEGRAN: ALTO MANDO, EJÉRCITO, \\
FUERZA AÉREA, FUERZA NAVAL, FUERZA DE \\
SEGURIDAD PÚBLICA, ORGANISMOS Y \\
DEPENDENCIAS QUE DETERMINE SU LEY \\
CONSTITUTIVA. \\
- \\
LA FUERZA ARMADA ES UNA INSTITUCIÓN \\
PERMANENTE. ES OBEDIENTE, PROFESIO- \\
NAL, APOLÍTICA Y NO DELIBERANTE. \\
- OBJETIVOS: DEFENDER INTEGRIDAD TERR- \\
TORIAL Y SOBERANÍA DE LA REPÚBLICA, \\
MANTENER LA PAZ, EL ORDEN PÚBLICO Y LA \\
CONSTITUCIÓN, LOS PRINCIPIOS DEL \\
SUFRAGIO Y LA ALTERNABILIDAD EN EL \\
EJERCICIO DE LA PRESIDENCIA DE LA \\
REPÚBLICA. \\
LA FUERZA ARMADA TIENE POR MISIÓN LA \\
DEFENSA DE LA SOBERANÍA DEL ESTADO Y \\
DE LA INTEGRIDAD DEL TERRITORIO. \\
LA FUERZA ARMADA DEBE COLABORAR \\
EN ALFABETIZACIÓN, EDUCACIÓN, AGRI- \\
CULTURA, CONSERVACIÓN DE RECURSOS \\
NATURALES, COMUNICACIONES, SANIDAD, \\
REFORMA AGRARIA Y SITUACIONES DE \\
EMERGENCIA. \\
PRESIDENTE ES COMANDANTE GENERAL \\
DE LA FUERZA ARMADA. \\
RESERVADA LA FACULTAD PRIVATIVA DE \\
LAS FUERZAS ARMADAS, LA FABRICACIÓN, \\
COMERCIO Y TENENCIA DE ARMAS, MUNI- \\
CIONES, EXPLOSIVOS Y ARTÍCULOS SIMI- \\
LARES. \\
\hline
\end{tabular}

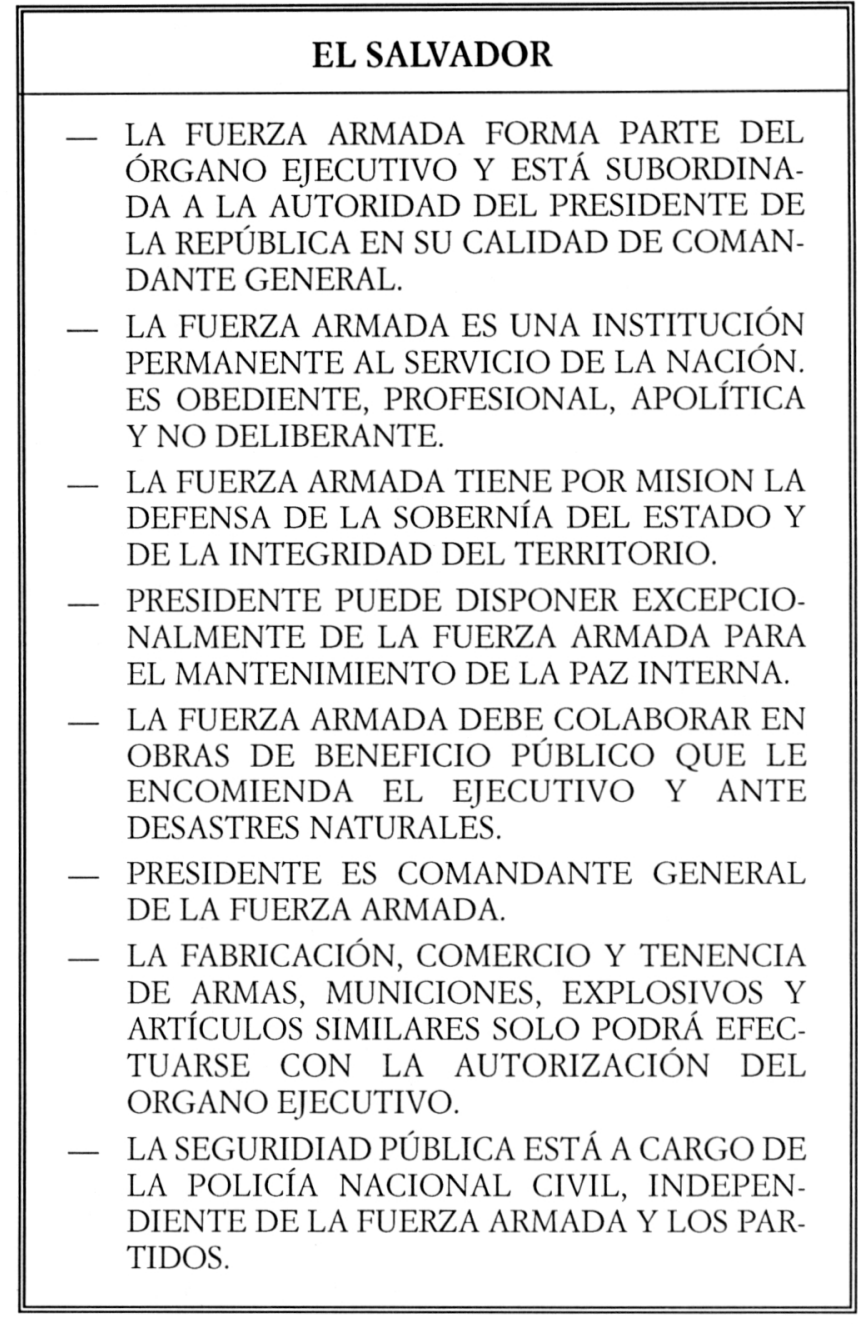

\section{NICARAGUA}

- El EJÉRCITO DE NICARAgUa tIENE CARÁCTER PROFESIONAL, APOLÍTICO, OBEDIENTE Y NO DELIBERANTE.

- SE SOMETE A LA AUTORIDAD CIVIL POR MEDIO DEL PRESIDENTE DE LA REPÚBLICA O DEL MINISTERIO CORRESPONDIENTE.

- FUNCIÓN: DEFENDER LA SOBERANÍA, LA INDEPENDENCIA Y LA INTEGRIDAD TERRITORIAL.

- SE ESTABLECE LA POLICÍA NACIONAL COMO CUERPO ARMADO DE NATURALEZA CIVIL, QUE GARANTIZA EL ORDEN INTERNO Y LA SEGURIDAD CIUDADANA.

- TANTO AL EJÉRCITO COMO A LA POLICÍA NACIONAL SE PROHIBE PARTICIPAR EN ACTOS DE CARÁCTER POLÍTICO.

- PROHIBIDO ESTABLECER BASES MILITARES EXTRANJERAS EN TERRITORIO NACIONAL. 


\section{LA CONSTITUCIÓN Y OTRAS ORGANIZACIONES SOCIALES}

\section{COSTA RICA}

- LOS HABITANTES DE LA REPÚBLICA TIENEN DERECHO ASOCIARSE PARA FINES LÍCITOS. NADIE PODRA SER OBLIGADO A FORMAR PARTE DE ASOCIACIÓN ALGUNA.

- TODOS TIENEN DERECHO DE REUNIRSE PACIFICAMENTE Y SIN ARMAS, YA SEA PARA NEGOCIOS PRIVADOS, O PARA DISCUTIR ASUNTOS POLÍTICOS Y EXAMINAR LA CONDUCTA PÚBLICA DE LOS FUNCIONARIOS.

- NADIE PUEDE SER INQUIETADO NI PERSEGUIDO POR LA MANIFESTACIÓN DE SUS OPINIONES NI POR ACTO ALGUNO QUE NO INFRINJA LA LEY.

- SON PROHIBIDOS LOS MONOPOLIOS DE CARÁCTER PARTICULAR Y CUALQUIER ACTO, AUNQUE FUERE ORIGINADO EN UNA LEY, QUE AMENACE O RESTRINJA LA LIBERTAD DE COMERCIO, AGRICULTURA E INDUSTRIA. ASÍ, LAS EMPRESAS CONSTITUIDAS EN MONOPOLIOS DEBEN SER SOMETIDAS A UNA LEGISLACION ESPECIAL.

- TANTO lOS PATRONOS COMO LOS TRABAJADORES PODRÁN SINDICALIZARSE LIBREMENTE, CON EL FIN EXCLUSIVO DE OBTENER Y CONSERVAR BENEFICIOS ECONÓMICOS, SOCIALES O PROFESIONALES.

- todos los ciudadanos tienEN DERECHO A AGRUPARSE EN PARTIDOS, PARA INTERVENIR EN LA POLÍTICA NACIONAL, SIEMPRE QUE ESTOS SE COMPROMETAN EN SUS PROGRAMAS A RESPETAR EL ORDEN CONSTITUCIONAL DE LA REPÚBLICA.

\section{EL SALVADOR}

- LOS HABITANTES DE EL SALVADOR TIENEN DERECHO ASOCIARSE LIBREMENTE Y A REUNIRSE PACIFICAMENTE Y SIN ARMAS PARA CUALQUIER OBJETO LÍCITO.

- SE GARANTIZA EL LIBRE EJERCICIO DE TODAS LAS RELIGIONES, SIN MÁS LÍMITES QUE EL TRAZADO POR LA MORAL Y EL ORDEN PÚBLICO.

- LOS PATRONOS Y TRABAJADORES PRIVADOS, SIN DISTINCIÓN DE NACIONALIDAD, SEXO, RAZA, CREDO O IDEAS POLÍTICAS Y CUALQUIERA QUE SEA SU ACTIVIDAD O LA NATURALEZA DEL TRABAJO QUE REALICEN, TIENEN EL DERECHO DE ASOCIARSE LIBREMENTE PARA LA DEFENSA DE SUS RESPECTIVOS INTERESES, FORMANDO ASOCIACIONES PROFESIONALES O SINDICATOS. AL IGUAL LOS TRABAJADORES DE LAS INSTITUCIONES OFICIALES AUTÓNOMAS.

- es DEREChO DEL CIUDADANO, ASOCIARSE PARA CONSTITUIR PARTIDOS POLÍTICOS DE ACUERDO CON LA LEY E INGRESAR A LOS YA CONSTITUÍDOS

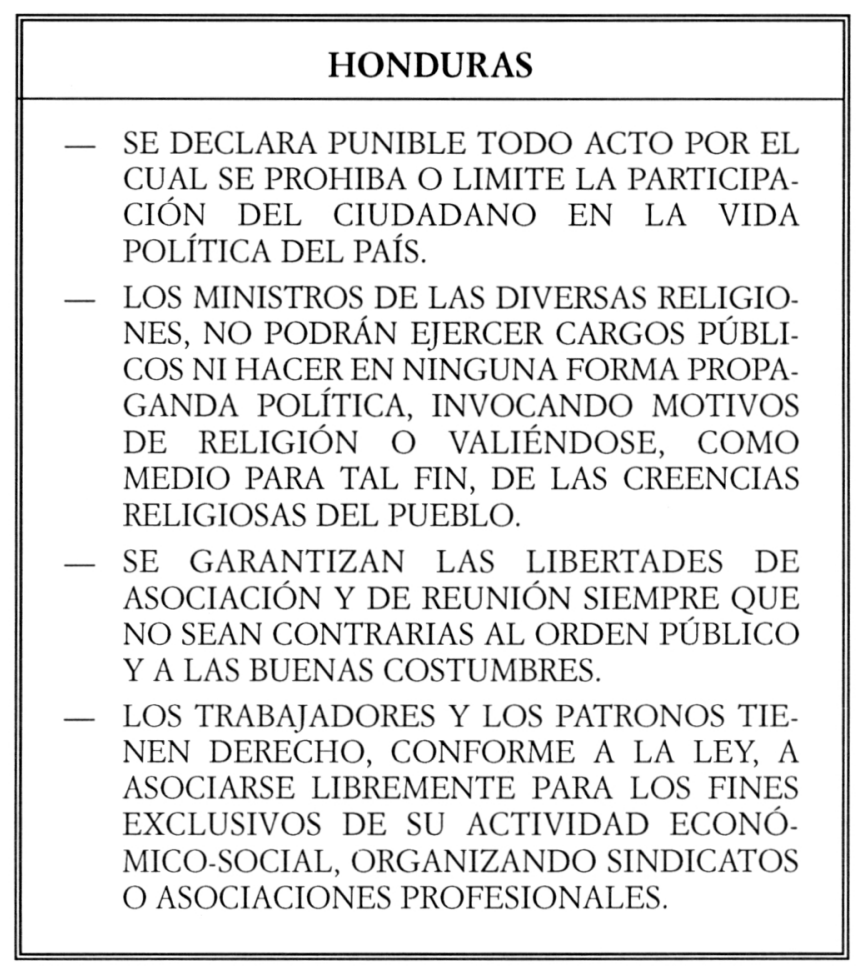

\begin{tabular}{|l}
\hline \multicolumn{1}{||}{ NICARAGUA } \\
\hline - \\
TIENEN DERECHO DE CONSTITUÍRSE EN \\
ORGANIZACIONES LOS TRABAJADORES DE \\
LA CIUDAD Y DEL CAMPO, LAS MUJERES, \\
LOS JÓVENES, LOS PRODUCTORES AGROPE- \\
CUARIOS, LOS ARTESANOS, LOS PROFESIO- \\
NALES, LOS TÉCNICOS, LOS INTELEC- \\
TUALES, LOS ARTISTAS, LOS RELIGIOSOS Y \\
LOS POBLADORES EN GENERAL, SIN DIS- \\
CRIMINACIÓN ALGUNA, CON EL FIN DE \\
LOGRAR LA REALIZACIÓN DE SUS ASPIRA- \\
CIONES SEGÚN SUS PROPIOS INTERESES Y \\
PARTICIPAR EN LA CONSTRUCCIÓN DE UNA \\
NUEVA SOCIEDAD. \\
ESTAS SE FORMARAN DE ACUERDO A LA \\
VOLUNTAD PARTICIPATIVA Y ELECTIVA DE \\
LOS CIUDADANOS, TENDRÁN UNA FUNCIÓN \\
SOCIAL Y PODRÁN O NO TENER CARÁCTER \\
PARTIDARIO, SEGÚN SUS INTERESES. \\
LOS CIUDADANOS TIENEN DERECHO DE \\
ORGANIZARSE O AFILIARSE A PARTIDOS \\
POLÍTICOS, CON EL FIN DE PARTICIPAR, \\
EJERCER Y OPTAR AL PODER. \\
- LOS TRABAJADORES TIENEN DERECHO DE \\
PARTICIPAR EN LA GESTIÓN DE LAS EMPRE- \\
SAS, POR MEDIO DE SUS ORGANIZACIONES \\
Y DE CONFORMIDAD CON LA LEY. \\
EXISTE PLENA LIBERTAD SINDICAL. LOS \\
TRABAJADORES SE ORGANIZAN VOLUNTA- \\
RIAMENTE EN SINDICATOS Y ESTOS PUE- \\
DEN CONSTITUÍRSE CONFORME LO ESTA- \\
BLECE LA LEY.
\end{tabular}


TABLA N. ${ }^{\circ}$ 1: AMENAZA O RIESGO PARA LA CONSOLIDACIÓN DE LA DEMOCRACIA

\begin{tabular}{||l|l|c|c|c|c||}
\hline \multicolumn{1}{||}{ AMENAZA } & RANGO DE & COSTA RICA & EL SALVADOR & HONDURAS & NICARAGUA \\
& IMPORTANCIA & & & & \\
\hline RELACIONES FUERZAS & MÍNIMA & 61,5 & 10,9 & 19,4 & 9,8 \\
ARMADAS Y & POCA & 13,5 & 21,7 & 13,4 & 14,6 \\
GOBIERNO & MEDIA & 13,5 & 23,9 & 32,8 & 22,0 \\
& IMPORTANTE & 0,0 & 21,7 & 19,4 & 26,8 \\
& MUY & 7,7 & 19,6 & 11,9 & 4,9 \\
& NC & 3,8 & 0,0 & 0,0 & 3,4 \\
& NS & 0,0 & 2,2 & 3,0 & 19,5 \\
\hline EL MAL & MÍNIMA & 11,5 & 19,6 & 1,5 & 2,4 \\
FUNCIONAMIENTO & POCO & 25,0 & 13,0 & 6,0 & 2,4 \\
DEL PODER JUDICIAL & MEDIA & 32,7 & 19,6 & 25,4 & 14,6 \\
& IMPORTA & 17,3 & 21,7 & 23,9 & 24,4 \\
& MUY & 11,5 & 26,1 & 41,8 & 56,1 \\
& NC & 1,9 & 0,0 & 0,0 & 0,0 \\
& NS & 0,0 & 0,0 & 1,5 & 0,0 \\
\hline CONFLICTO ENTRE & MÍNIMA & 26,5 & & 22,4 & 2,4 \\
EJECUTIVO Y & POCO & 15,4 & & 16,4 & 26,8 \\
LEGISLATIVO & MEDIA & 21,2 & & 19,4 & 29,3 \\
& IMPORTA & 25,0 & & 2,9 & 22,0 \\
& MUY & 9,6 & & 17,9 & 17,1 \\
& NC & 1,9 & & 0,0 & 2,4 \\
& NS & 0,0 & & 3,0 & 0,0 \\
\hline
\end{tabular}

\section{LOS PARLAMENTARIOS Y EL EJECUTIVO}

La encuesta que sustenta las apreciaciones que se señalan a continuación, permite identificar algunos indicadores para analizar el rol del Ejecutivo desde la perspectiva de los parlamentarios centroamericanos, así como sus consideraciones sobre el peso que las relaciones entre ambos poderes tiene en la dinámica política de sus respectivos países. Es preciso señalar que para los objetivos de este trabajo las variables que refieren al papel del Estado (capacidad del Estado para resolver problemas de la sociedad y rol de intervención del Estado) se han identificado con papel del Ejecutivo.

Es claro que esta reducción del Estado al Ejecutivo es no solamente insuficiente y esquemática, sino que puede llevar a la falsa presunción de adjudicar una racionalidad al Ejecutivo que parece resaltar la preeminencia que éste ha tenido en los países de la región, por encima de los otros poderes del Estado. De ahí que es necesario aclarar que el fin de hacer esta correspondencia apunta a la credibilidad que los mismos parlamentarios le adjudican a la dinámica que se genera en la relación entre los poderes del Estado, de suerte tal que al juzgarlo como desde fuera, permite visualizar la percepción del juego de poder que se gesta en la institucionalidad estatal en la cual el Ejecutivo, en sistemas presidencialistas como los centroamericanos, sin duda que asumen un papel titular en la orientación de las políticas económicas y sociales y en los ámbitos de expansión del Estado en las diversas áreas del desarrollo nacional.

Parece haber acuerdo en los parlamentarios de la región que el Estado tiene capacidad para resolver los problemas sociales. La diferencia radica en cómo esa capacidad se traduce en resolver la multiplicidad de los problemas que afectan a la sociedad. Los diputados salvadoreños $(65,2 \%)$ son los que apuestan más por el Estado como capaz resolver muchos de los problemas sociales, seguidos por los costarricenses $(57,7)$. Mientras que los nicaraguenses y hondureños no llegan a la mitad quienes consideran que puede resolver muchos problemas, aunque coinciden en que puede hacerlo en relación a pocos o algunos problemas (Ver Tabla n. ${ }^{\circ} 2$ )

TABLA N." 2: AMENAZA O RIESGO PARA LA CONSOLIDACIÓN DE LA DEMOCRACIA

\begin{tabular}{||l|c|c|c|c||}
\hline RANGO DE & COSTA RICA & EL SALVADOR & HONDURAS & NICARAGUA \\
IMPORTANCIA & $15,4 \%$ & $15,2 \%$ & $22,4 \%$ & $9,8 \%$ \\
\hline LA MAYORÍA & $42,3 \%$ & $50,0 \%$ & $23,9 \%$ & $22,0 \%$ \\
BASTANTES & $38,5 \%$ & $34,8 \%$ & $53,7 \%$ & $61,0 \%$ \\
ALGUNOS & $3,8 \%$ & $0,0 \%$ & $0,0 \%$ & $7,3 \%$ \\
MUY POCOS & $0,0 \%$ & $0,0 \%$ & $0,0 \%$ & $0,0 \%$ \\
NINGUNO & $100,0 \%$ & $100,0 \%$ & $100,0 \%$ & $100,0 \%$ \\
\hline TOTAL & \multicolumn{2}{|l}{} \\
\hline
\end{tabular}


Es interesante identificar la relación que se establece entre la capacidad de los Estado de resolver los problemas sociales y los roles de intervención que deben asumir en las diversas áreas del desarrollo nacional (Tabla n. ${ }^{\circ} 3$ ) . En este sentido, al ser consultados sobre el papel del Estado en la educación, coinciden en un intervencionismo estatal determinante en las áreas de educación, que garantice enseñanza primaria y secundaria general y gratuita; así como en la protección del medio ambiente. Le sigue la opción por la acción estatal en la garantía de seguridad social, que supera el $60 \%$ en todos los casos y que en el caso de los diputados costarricenses significa junto con la educación la intervención estatal por excelencia. Aunque hay que destacar el hecho de que la educación superior constituye una prioridad de menor importancia que la primaria y media. Siendo así que la opinión de los diputados está dividida respecto del tema.

En Costa Rica y Nicaragua casi el 50\% de los diputados consideran que el Estado debe tener poca intervención en facilitar una educación universitaria general y gratuita. Mientras que en El Salvador y Honduras solamente una cuarta parte creen que debe tener poca intervención y tres cuartas partes se decantan por mucha intervención también en la educación universitaria ${ }^{4}$.

\section{Gráfico 10}

\section{Centroamérica: Nivel de intervención estatal en garantizar seguridad social}

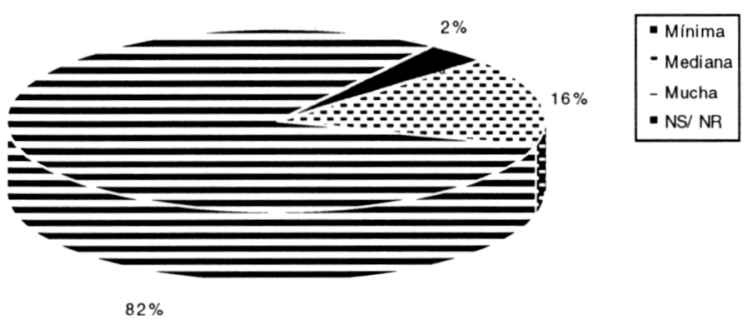

\section{Gráfico 8}

\section{Costa Rica y El Salvador: Nivel de intervención del Estado en la educación universitaria}

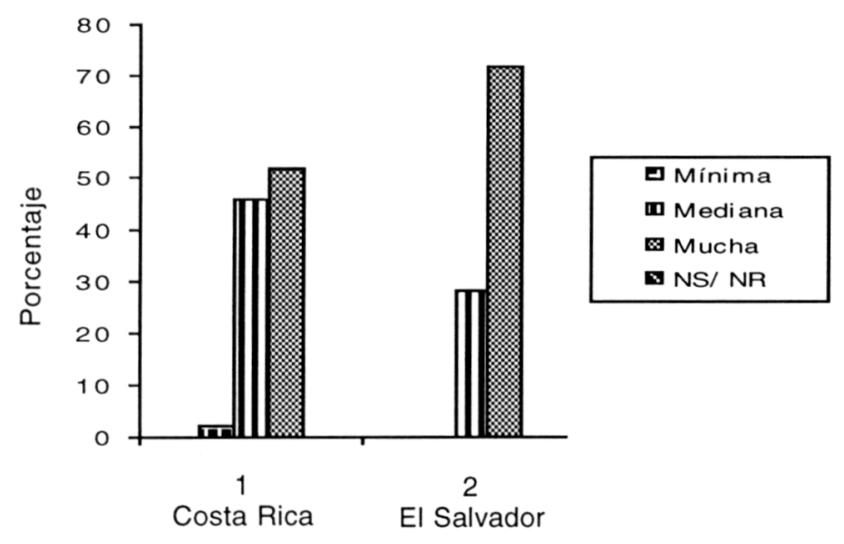

La vivienda, que es otra de las cuestiones que se plantean sobre la intervención estatal revela también diferencias entre los diputados de la región. En Costa Rica, Honduras y Nicaragua más de la mitad considera que el Estado debe ejercer mucha intervención en proveer de vivienda a los ciudadanos $(67,3 ; 53,7 ; 65,8$; respectivamente). Sólo en El Salvador se considera que la intervención en este campo debe ser reducida o poca $(58,7)$.

Es interesante destacar que el seguro de desempleo, que es una política estatal que no está presente en los países centroamericanos, es apoyado mayoritariamente como objeto de mucha intervención por los diputados costarricenses y hondureños $(59,6$ y 56,7$)$. No ocurre asî para los salvadoreños y nicaragüenses que consideran en casi un $75 \%$ que el Estado debe tener poca o ninguna intervención en seguros de desempleo. La crisis del empleo en los países centroamericanos no parece subsanarse mediante este tipo apoyo estatal o bien, el Estado no está en capacidad de brindar ese tipo de políticas de compensación.

La cuestión del empleo se complejiza aún más si se compara con la valoración que los diputados le asignan al Estado como empleador. En Costa Rica, donde el Estado tradicionalmente ha tenido un papel importante como proveedor de empleo, el 55,\% de los diputados consideran que el Estado debe tener poca o ninguna intervención en este aspecto. Esto es más significativo en El Salvador $(58,7 \%)$ y en Nicaragua $(65,8 \%)$. El caso de Honduras revela una opinión dividida en la cual una mitad apoya la opción de Estado empleador, mientras la otra considera que la intervención debe ser poca o ninguna.

El control de precios y el subsidio de productos de consumo básico, revela una acción del Estado que parece priorizar una liberalización que favorezca al mercado en la determinación de los costos de producción y consumo. En Costa Rica, El Salvador y Nicaragua supera el $60 \%$ quienes consideran que el Estado debe tener poca o ninguna intervención en cuanto a subsidios de la canasta básica. En consecuencia se observa también que el Estado no debe tener gran injerencia en el control de los precios. Honduras puede considerarse una excepción en tanto la relación se expresa exactamente en sentido inverso, en tanto el $60 \%$ apuesta por un intervencionismo en subsidios y control de precios y el $40 \%$ se inclina por una menor intervención en estos ámbitos.

4. A efectos del carácter ilustrativo de los gráficos, es preciso aclarar que la necesidad de intervención estatal, según la perciben los parlamentarios, ha sido agregada de la siguiente manera, en relación a los rangos establecidos en la encuesta original: mínima=mínima; poca+alguna= mediana; mucha+máxima=mucha; $\mathrm{NC}+\mathrm{NS}=\mathrm{NS} / \mathrm{NR}$ 


\begin{tabular}{|c|c|c|c|c|c|}
\hline CATEGORÍA & $\begin{array}{l}\text { RANGO DE } \\
\text { INTERVENCION }\end{array}$ & COSTA RICA & EL SALVADOR & HONDURAS & NICARAGUA \\
\hline $\begin{array}{l}\text { CONTROL } \\
\text { DE PRECIOS }\end{array}$ & $\begin{array}{l}\text { MÍNIMA } \\
\text { POCA } \\
\text { ALGUNA } \\
\text { MUCHA } \\
\text { MÁXIMA } \\
\text { NC } \\
\text { NS }\end{array}$ & $\begin{array}{r}9,6 \% \\
15,4 \% \\
17,3 \% \\
23,1 \% \\
31,6 \% \\
0,0 \% \\
0,0 \%\end{array}$ & $\begin{array}{r}30,4 \% \\
15,2 \% \\
30,4 \% \\
13,0 \% \\
10,9 \% \\
0,0 \% \\
0,0 \%\end{array}$ & $\begin{array}{r}13,4 \% \\
9,0 \% \\
9,0 \% \\
10,4 \% \\
50,7 \% \\
1,5 \% \\
6,0 \%\end{array}$ & $\begin{array}{r}9,8 \% \\
14,6 \% \\
31,7 \% \\
19,5 \% \\
22,0 \% \\
2,4 \% \\
0,0 \%\end{array}$ \\
\hline TRABAJO & $\begin{array}{l}\text { MÍNIMA } \\
\text { POCA } \\
\text { ALGUNA } \\
\text { MUCHA } \\
\text { MÁXIMA } \\
\text { NC } \\
\text { NS }\end{array}$ & $\begin{array}{r}9,6 \% \\
30,8 \% \\
15,4 \% \\
17,3 \% \\
26,9 \% \\
0,0 \% \\
0,0 \%\end{array}$ & $\begin{array}{r}17,4 \% \\
19,6 \% \\
21,7 \% \\
15,2 \% \\
26,1 \% \\
0,0 \% \\
0,0 \%\end{array}$ & $\begin{array}{r}13,4 \% \\
11,9 \% \\
14,9 \% \\
11,9 \% \\
40,3 \% \\
1,5 \% \\
6,0 \%\end{array}$ & $\begin{array}{r}7,3 \% \\
26,8 \% \\
31,7 \% \\
19,5 \% \\
14,6 \% \\
0,0 \% \\
0,0 \%\end{array}$ \\
\hline $\begin{array}{l}\text { EDUCACIÓN } \\
\text { PRIMARIA }\end{array}$ & $\begin{array}{l}\text { MÍNIMA } \\
\text { POCA } \\
\text { ALGUNA } \\
\text { MUCHA } \\
\text { MÁXIMA } \\
\text { NC } \\
\text { NS }\end{array}$ & $\begin{array}{r}0,0 \% \\
0,0 \% \\
0,0 \% \\
5,8 \% \\
94,2 \% \\
0,0 \% \\
0,0 \%\end{array}$ & $\begin{array}{r}0,0 \% \\
0,0 \% \\
2,2 \% \\
4,3 \% \\
93,5 \% \\
0,0 \% \\
0,0 \%\end{array}$ & $\begin{array}{r}1,5 \% \\
1,5 \% \\
1,5 \% \\
6,0 \% \\
82,1 \% \\
1,5 \% \\
6,0 \%\end{array}$ & $\begin{array}{r}4,9 \% \\
0,0 \% \\
9,8 \% \\
9,8 \% \\
75,6 \% \\
0,0 \% \\
0,0 \%\end{array}$ \\
\hline $\begin{array}{l}\text { EDUCACIÓN } \\
\text { SECUNDARIA }\end{array}$ & $\begin{array}{l}\text { MÍNIMA } \\
\text { POCA } \\
\text { ALGUNA } \\
\text { MUCHA } \\
\text { MÁXIMA } \\
\text { NC } \\
\text { NS }\end{array}$ & $\begin{array}{r}0,0 \% \\
0,0 \% \\
0,0 \% \\
17,3 \% \\
82,7 \% \\
0,0 \% \\
0,0 \%\end{array}$ & $\begin{array}{r}0,0 \% \\
4,3 \% \\
10,9 \% \\
17,4 \% \\
67,4 \% \\
0,0 \% \\
0,0 \%\end{array}$ & $\begin{array}{r}1,5 \% \\
1,5 \% \\
6,0 \% \\
13,4 \% \\
70,1 \% \\
1,5 \% \\
6,0 \%\end{array}$ & $\begin{array}{r}4,9 \% \\
0,0 \% \\
26,8 \% \\
22,0 \% \\
46,3 \% \\
0,0 \% \\
0,0 \%\end{array}$ \\
\hline $\begin{array}{l}\text { EDUCACIÓN } \\
\text { UNIVERSITARIA }\end{array}$ & $\begin{array}{l}\text { MÍNIMA } \\
\text { POCA } \\
\text { ALGUNA } \\
\text { MUCHA } \\
\text { MÁXIMA } \\
\text { NC } \\
\text { NS }\end{array}$ & $\begin{array}{r}1,9 \% \\
9,6 \% \\
36,5 \% \\
25,0 \% \\
26,9 \% \\
0,0 \% \\
0,0 \%\end{array}$ & $\begin{array}{r}0,0 \% \\
8,7 \% \\
19,6 \% \\
39,1 \% \\
32,6 \% \\
0,0 \% \\
0,0 \%\end{array}$ & $\begin{array}{r}4,5 \% \\
7,5 \% \\
13,4 \% \\
20,9 \% \\
46,3 \% \\
1,5 \% \\
6,0 \%\end{array}$ & $\begin{array}{r}2,4 \% \\
12,2 \% \\
31,7 \% \\
34,1 \% \\
19,5 \% \\
0,0 \% \\
0,0 \%\end{array}$ \\
\hline VIVENDA & $\begin{array}{l}\text { MÍNIMA } \\
\text { POCA } \\
\text { ALGUNA } \\
\text { MUCHA } \\
\text { MÁXIMA } \\
\text { NC } \\
\text { NS }\end{array}$ & $\begin{array}{r}1,9 \% \\
13,5 \% \\
17,3 \% \\
25,0 \% \\
42,3 \% \\
0,0 \% \\
0,0 \% \\
\end{array}$ & $\begin{array}{r}4,3 \% \\
13,0 \% \\
45,7 \% \\
17,4 \% \\
19,6 \% \\
0,0 \% \\
0,0 \% \\
\end{array}$ & $\begin{array}{r}3,0 \% \\
9,0 \% \\
25,4 \% \\
10,4 \% \\
43,3 \% \\
3,0 \% \\
6,0 \% \\
\end{array}$ & $\begin{array}{r}2,4 \% \\
2,4 \% \\
29,3 \% \\
31,7 \% \\
34,1 \% \\
0,0 \% \\
0,0 \% \\
\end{array}$ \\
\hline $\begin{array}{l}\text { SEGURIDAD } \\
\text { SOCIAL }\end{array}$ & $\begin{array}{l}\text { MÍNIMA } \\
\text { POCA } \\
\text { ALGUNA } \\
\text { MUCHA } \\
\text { MÁXIMA } \\
\text { NC } \\
\text { NS }\end{array}$ & $\begin{array}{r}0,0 \% \\
1,9 \% \\
0,0 \% \\
17,3 \% \\
80,8 \% \\
0,0 \% \\
0,0 \%\end{array}$ & $\begin{array}{r}0,0 \% \\
13,0 \% \\
17,4 \% \\
21,7 \% \\
47,8 \% \\
0,0 \% \\
0,0 \%\end{array}$ & $\begin{array}{r}0,0 \% \\
4,5 \% \\
3,0 \% \\
14,9 \% \\
70,1 \% \\
1,5 \% \\
6,0 \%\end{array}$ & $\begin{array}{r}0,0 \% \\
2,4 \% \\
34,1 \% \\
19,5 \% \\
41,5 \% \\
2,4 \% \\
0,0 \%\end{array}$ \\
\hline $\begin{array}{l}\text { SEGURO DE } \\
\text { DESEMPLEO }\end{array}$ & $\begin{array}{l}\text { MÍNIMA } \\
\text { POCA } \\
\text { ALGUNA } \\
\text { MUCHA } \\
\text { MÁXIMA } \\
\text { NC } \\
\text { NS }\end{array}$ & $\begin{array}{r}3,8 \% \\
13,5 \% \\
23,1 \% \\
30,8 \% \\
28,8 \% \\
0,0 \% \\
0,0 \%\end{array}$ & $\begin{array}{r}15,2 \% \\
34,8 \% \\
21,7 \% \\
15,2 \% \\
10,9 \% \\
2,2 \% \\
0,0 \%\end{array}$ & $\begin{array}{r}7,5 \% \\
7,5 \% \\
20,9 \% \\
20,9 \% \\
35,8 \% \\
1,5 \% \\
6,0 \%\end{array}$ & $\begin{array}{r}0,0 \% \\
17,1 \% \\
43,9 \% \\
14,6 \% \\
17,1 \% \\
7,3 \% \\
0,0 \%\end{array}$ \\
\hline $\begin{array}{l}\text { SUBSIDIOS } \\
\text { CANASTA BÁSICA }\end{array}$ & $\begin{array}{l}\text { MÍNIMA } \\
\text { POCA } \\
\text { ALGUNA } \\
\text { MUCHA } \\
\text { MÁXIMA } \\
\text { NC } \\
\text { NS }\end{array}$ & $\begin{array}{r}15,4 \% \\
21,2 \% \\
26,9 \% \\
15,4 \% \\
21,2 \% \\
0,0 \% \\
0,0 \%\end{array}$ & $\begin{array}{r}26,1 \% \\
23,9 \% \\
17,4 \% \\
13,0 \% \\
19,6 \% \\
0,0 \% \\
0,0 \%\end{array}$ & $\begin{array}{r}4,5 \% \\
7,5 \% \\
29,9 \% \\
11,9 \% \\
38,8 \% \\
1,5 \% \\
6,0 \%\end{array}$ & $\begin{array}{r}7,3 \% \\
12,2 \% \\
51,2 \% \\
14,6 \% \\
9,8 \% \\
4,9 \% \\
0,0 \%\end{array}$ \\
\hline MEDIO AMBIENTE & $\begin{array}{l}\text { MÍNIMA } \\
\text { POCA } \\
\text { ALGUNA } \\
\text { MUCHA } \\
\text { MÁXIMA } \\
\text { NC } \\
\text { NS }\end{array}$ & $\begin{array}{r}0,0 \% \\
0,0 \% \\
1,9 \% \\
3,8 \% \\
94,2 \% \\
0,0 \% \\
0,0 \%\end{array}$ & $\begin{array}{r}0,0 \% \\
0,0 \% \\
0,0 \% \\
8,7 \% \\
91,3 \% \\
0,0 \% \\
0,0 \%\end{array}$ & $\begin{array}{r}1,5 \% \\
0,0 \% \\
0,0 \% \\
4,5 \% \\
86,6 \% \\
1,5 \% \\
6,0 \%\end{array}$ & \begin{tabular}{r|}
$2,4 \%$ \\
$2,4 \%$ \\
$4,9 \%$ \\
$17,1 \%$ \\
$73,2 \%$ \\
$0,0 \%$ \\
$0,0 \%$
\end{tabular} \\
\hline
\end{tabular}


Gráfico 9

Honduras y Nicaragua: Nivel de intervención estatal en el control de precios

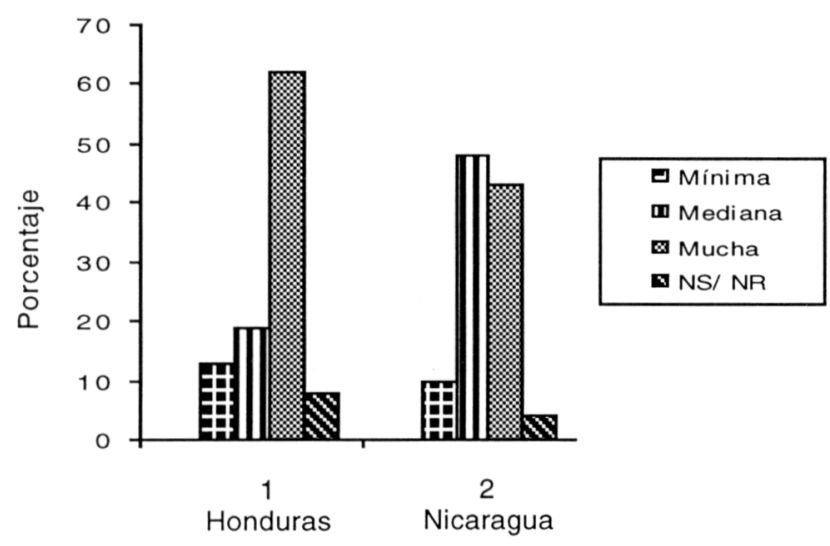

\subsection{Las relaciones Legislativo-y otros Poderes del Estado}

Las relaciones entre los poderes del Estado en Centroamérica resultan ser una cuestión de especial interés al identificar la importancia que se les adjudica en el marco de un conjunto de problemas comunes en América Latina (Ver Tabla no. 4). Costa Rica, El Salvador y Honduras coinciden en afirmar que las relaciones entre poderes en sus países no son muy conflictivas $(65,4 \%$; $69,6 \% ; 67,2 \%)$. Lo anterior en el entendido de que las diferencias entre poderes no se traducen en conflictos que aprobación de las reformas constitucionales en la Asamblea Nacional, de febrero de 1995. La negativa del Ejecutivo a sancionar las reformas a la Constitución de 1987 que implicaban una redefinición de las funciones de los distintos poderes ${ }^{5}$ desató una crisis de varios meses que contribuye a explicar la percepción de los nicaraguenses respecto de la conflictividad de sus relaciones con el Ejecutivo y el Judicial ${ }^{6}$.

\section{Gráfico 11}

Centroamérica: Nivel de importancia del conflicto entre Poderes del Estado como problema común de los países

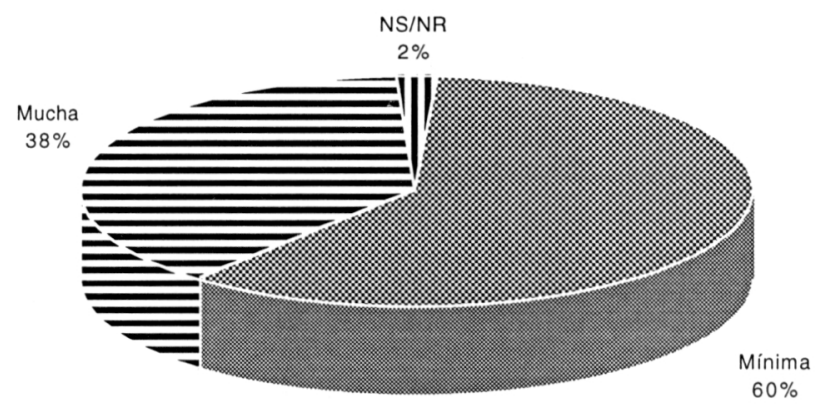

TABLA N.” 4: PROBLEMAS COMUNES EN CENTROAMÉRICA

\begin{tabular}{|c|c|c|c|c|c|}
\hline $\begin{array}{l}\text { PROBLEMAS } \\
\text { COMUNES }\end{array}$ & $\begin{array}{l}\text { RANGO DE } \\
\text { IMPORTANCIA }\end{array}$ & COSTA RICA & EL SALVADOR & HONDURAS & NICARAGUA \\
\hline $\begin{array}{l}\text { RELACIONES FUERZAS } \\
\text { ARMADAS Y } \\
\text { POLICIALES }\end{array}$ & $\begin{array}{l}\text { MÍNIMA } \\
\text { POCA } \\
\text { INDIFERENTE } \\
\text { IMPORTANTE } \\
\text { MÁXIMA } \\
\text { NC } \\
\text { NS }\end{array}$ & $\begin{array}{r}34,6 \\
40,4 \\
9,6 \\
7,7 \\
7,7 \\
0,0 \\
0,0\end{array}$ & $\begin{array}{r}19,6 \\
26,1 \\
32,6 \\
15,2 \\
4,3 \\
2,2 \\
0,0\end{array}$ & $\begin{array}{r}11,9 \\
20,9 \\
29,9 \\
20,9 \\
11,9 \\
0,0 \\
4,5\end{array}$ & $\begin{array}{r}4,9 \\
29,3 \\
34,1 \\
17,1 \\
12,9 \\
2,4 \\
0,0\end{array}$ \\
\hline $\begin{array}{l}\text { CONFLICTO PODERES } \\
\text { DEL ESTADO }\end{array}$ & $\begin{array}{l}\text { MÍNIMA } \\
\text { POCO } \\
\text { INDIFERENTE } \\
\text { IMPORTANTE } \\
\text { MÁXIMA } \\
\text { NC } \\
\text { NS }\end{array}$ & $\begin{array}{r}19,2 \\
15,4 \\
30,8 \\
23,1 \\
11,5 \\
0,0 \\
0,0\end{array}$ & $\begin{array}{r}15,2 \\
28,3 \\
26,1 \\
19,6 \\
10,9 \\
0,0 \\
0,0\end{array}$ & $\begin{array}{r}22,4 \\
22,4 \\
22,4 \\
10,4 \\
17,9 \\
0,0 \\
4,5\end{array}$ & $\begin{array}{r}0,0 \\
12,2 \\
14,6 \\
34,1 \\
39,0 \\
0,0 \\
0,0\end{array}$ \\
\hline
\end{tabular}

amenazan la estabilidad política. Lo contrario ocurre en el caso nicaragüense donde tres cuartas partes de los parlamentarios valoran como muy conflictivas las relaciones entre poderes.

Es interesante ubicar el contexto en que esta encuesta fue realizada en ese país, el cual experimenta la crisis institucional más grave desde las elecciones de 1990, con la
5. Véase: Panorama Centroamericano. \#105. INCEP. Guatemala, Junio de 1995

6. El nivel de importancia del conflicto entre poderes del Estado, como problemas compartidos con el conjunto de los países latinoamericanos, según la perciben los parlamentarios, ha sido agregada de la siguiente manera, en relación a los rangos establecidos en la encuesta original: mínima=mínima; poca+indiferente= mediana; importante + máxi$\mathrm{ma}=$ mucha; $\mathrm{NC}+\mathrm{NS}=\mathrm{NS} / \mathrm{NR}$ 


\section{Gráfico 12}

Nicaragua: Nivel de importancia del conflicto entre Poderes del Estado como problema común de los países centroamericanos

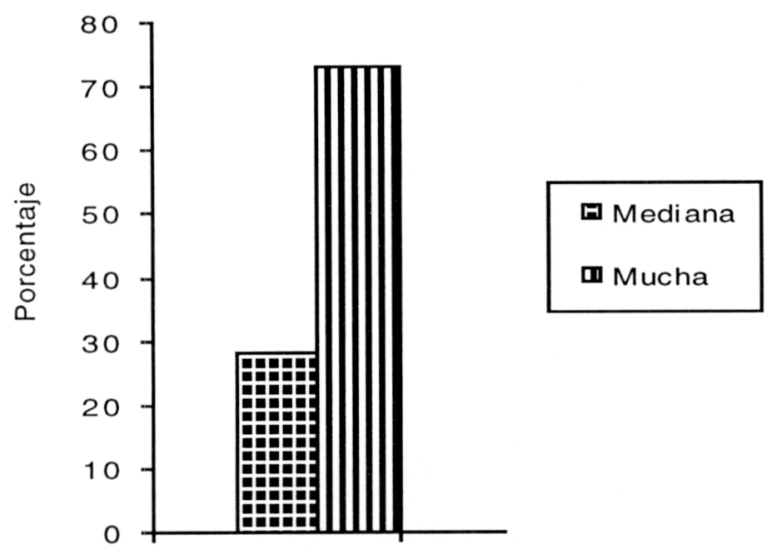

Nicaragua

Tal vez ello explica el que, para el caso de Nicaragua, el conflicto entre poderes se perciba como un riesgo para la consolidación de la democracia (Ver Tabla n. ${ }^{\circ}$ 1) Si se analiza el funcionamiento del Poder Judicial, parece sin embargo haber más acuerdo entre los parlamentarios sobre las implicaciones que ello tiene para las democracias de estos países. Los diputados hondureños y nicaraguenses coinciden en afirmar que el mal funcionamiento del Poder Judicial se constituye en una importante amenaza a la consolidación democrática $(65, \& \%$ y 80,5\%) de sus países; mientras que en Costa Rica el 70\% considera que ésta no es una amenaza y El Salvador mantiene la opinión dividida por la mitad entre quienes creen que el funcionamiento del poder juducial afecta positiva o negativamente la consolidación de la democracia en ese país ${ }^{7}$.

\section{Gráfico 3}

Centroamérica: El mal funcionamiento del Poder Judicial como amenaza o riesgo para la consolidación democrática

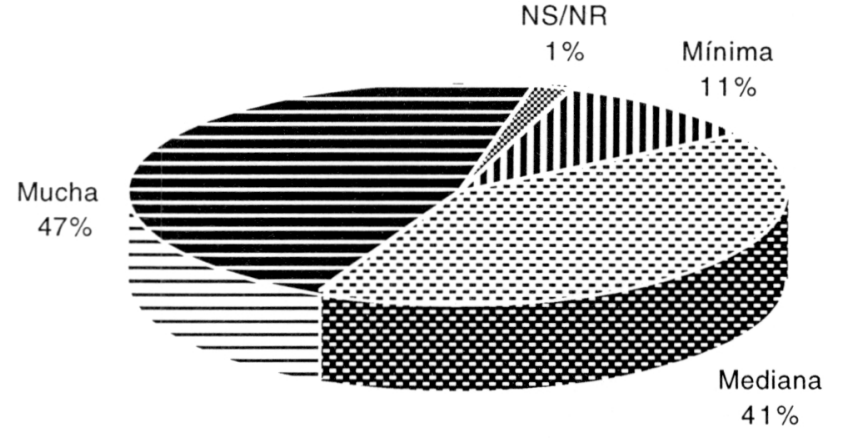

\section{Gráfico 4}

Nicaragua: El mal funcionamiento del Poder Judicial como amenaza o riesgo para la consolidación democrática

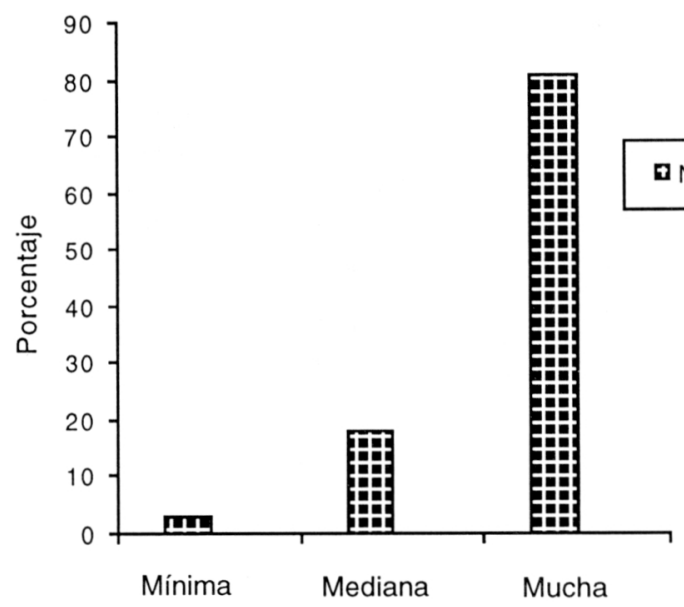

Nivel de amenaza

Gráfico 5

Centroamérica: Conflicto entre Legislativo y Ejecutivo como amenaza o riesgo para la consolidación democrática

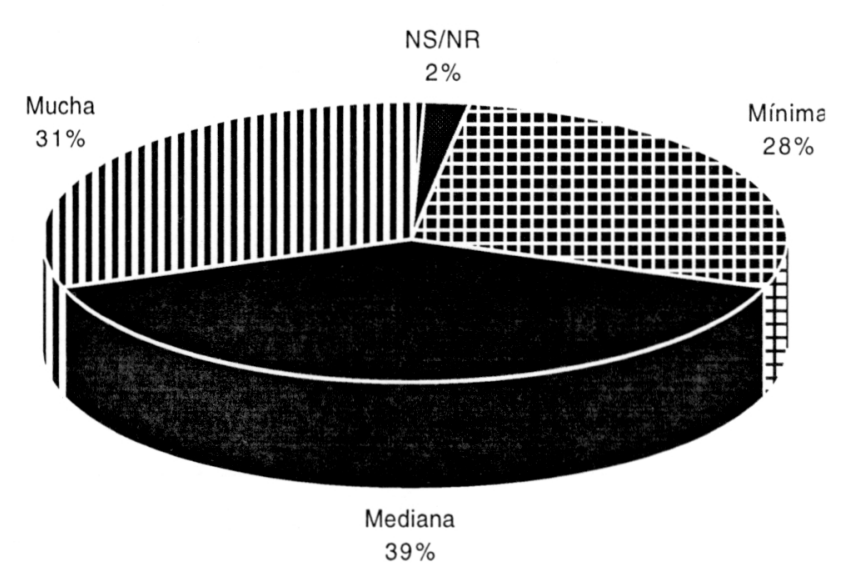

7. El nivel de amenza o riesgo para la consolidación democrática, según la perciben los parlamentarios, ha sido agregada de la siguiente manera, en relación a los rangos establecidos en la encuesta original: mínima=mínima; poca + mediana $=$ mediana; importante + muy importan te=mucha; $\mathrm{NC}+\mathrm{NS}=\mathrm{NS} / \mathrm{NR}$ 


\begin{tabular}{|c|c|c|c|c|c|}
\hline PERÍODO & RANGO & COSTA RICA & EL SALVADOR & HONDURAS & NICARAGUA \\
\hline $1970-1990$ & $\begin{array}{l}\text { MUY NEGATIVO } \\
\text { NEGATIVO } \\
\text { INDIFERENTE } \\
\text { POSITIVO } \\
\text { MUY POSITIVO } \\
\text { NC } \\
\text { NS }\end{array}$ & $\begin{array}{r}3,8 \\
9,6 \\
46,2 \\
25,0 \\
11,5 \\
3,8 \\
0,0\end{array}$ & $\begin{array}{r}39,1 \\
15,2 \\
28,3 \\
6,5 \\
8,7 \\
2,2 \\
0,0\end{array}$ & $\begin{array}{r}17,9 \\
20,9 \\
46,3 \\
11,9 \\
3,0 \\
0,0 \\
0,0\end{array}$ & $\begin{array}{r}26,8 \\
12,2 \\
17,1 \\
14,6 \\
24,4 \\
4,9 \\
0,0\end{array}$ \\
\hline $1990-1995$ & $\begin{array}{l}\text { MUY NEGATIVO } \\
\text { NEGATIVO } \\
\text { INDIFERENTE } \\
\text { POSITIVO } \\
\text { MUY POSITIVO } \\
\text { NC } \\
\text { NS }\end{array}$ & $\begin{array}{r}3,8 \\
21,2 \\
50,0 \\
17,3 \\
5,8 \\
1,9 \\
0,0\end{array}$ & $\begin{array}{r}0,0 \\
10,9 \\
39,1 \\
26,1 \\
21,7 \\
2,2 \\
0,0\end{array}$ & $\begin{array}{r}3,0 \\
11,9 \\
55,2 \\
26,9 \\
3,0 \\
0,0 \\
0,0\end{array}$ & $\begin{array}{r}12,2 \\
14,6 \\
19,5 \\
24,4 \\
26,8 \\
2,4 \\
0,0\end{array}$ \\
\hline
\end{tabular}

Gráfico 6

\section{Nicaragua: Conflicto entre el Legislativo y Ejecutivo como riesgo o amenaza para la consolidación democrática}

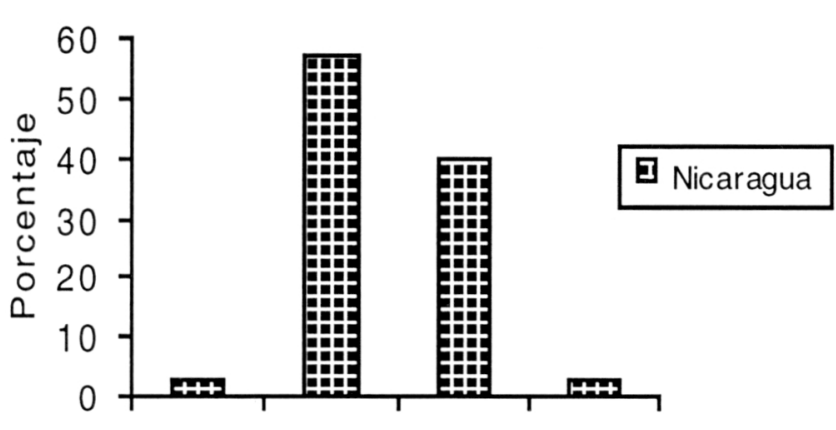

Mínima Media Mucha NS/ NR

Nivel de amenaza

\section{LOS PARLAMENTARIOS Y LAS FUERZAS ARMADAS}

Cuando se interpela a los diputados centroamericanos respecto de valorar el papel de las Fuerzas Armadas entre diversos problemas considerados comunes en el contexto latinoamericano, todos superan el $60 \%$ cuando afirman que éste es un problema poco importante en cada uno de sus países. En el caso costarricense esta opinión llega al $85 \%$, lo que se explica por la no existencia de Fuerzas Armadas como tales y porque la pregunta les fue planteada en relación únicamente a sus fuerzas policiales ${ }^{8}$.

No obstante, la percepción sobre el papel de los ejércitos en estos países, se valora de manera distinta si se evalúa su gestión durante las década de 1970 y 1980 (Ver Tabla n." 5) En Costa Rica, la valoración de sus fuerzas de seguridad pública es muy positiva, lo cual contrasta con la percepción de los parlamentarios salvadoreños y hondure- ños, quienes mayoritariamente califican muy negativo el papel desempeñado por las fuerzas armadas durante este período. En Nicaragua la opinión está dividida por la mitad en términos de valorar positiva o negativamente el papel de las fuerzas armadas entre 1970 y 1990.

No es casual que se haya decidido hacer la especificidad de la evaluación del papel de las fuerzas armadas a partir de 1990, año que se constituye en el punto de inflexión para Centroamérica, por las históricas elecciones que le dan el triunfo a la UNO en Nicaragua, y en el que se encamina el proceso hacia los acuerdos de Paz de El Salvador en Chapultepec de 1992; a la vez que coincide con procesos electorales más consolidados y reconocidos en todos los países

Es notorio el cambio en la valoración que se hace de las fuerzas armadas por parte de quienes habían considerado su papel muy negativo durante las dos décadas anteriores. Tal es el caso de El Salvador, Honduras, y Nicaragua en los que la valoración pasa a ser positiva en promedio aunque en Nicaragua la cuarta parte de los diputados sigue considerando el rol de las fuerzas armadas como negativo también en los últimos años. El caso de Costa Rica revela también un cambio importante en la valoración de sus fuerzas policiales que reciben una ponderación negativa o muy negativa de una cuarta parte del total de los diputados entrevistados. Las acusaciones de corrupción y violencia que ha salpicado a la fuerza pública no parece escapar a la mirada de los parlamentarios al momento de ponderar su rol del último quinquenio.

A partir de esta evaluación general, es que adquiere sentido la consulta sobre el papel que las fuerzas armadas deben tener de cara al próximo siglo (Tabla n. ${ }^{\circ} 6$ ). Costa Rica, Honduras y El Salvador coinciden en afirmar como principal labor a desempeñar por las fuerzas armadas, la

8. Este aspecto debe ser entendido así sólo si se refiere a valorar sus propias fuerzas de seguridad pública, si se trata de valorar las fuerzas armadas en el contexto regional, está claro que la opinión de los diputados refiere al papel de los ejércitos en los demás países y en general en el conjunto de la región centroamericana. 
TABLA N. ${ }^{\circ}$ 6: PAPEL DE LAS FUERZAS ARMADAS SIGLO XXI

\begin{tabular}{||l|l|c|c|c|c||}
\hline \multirow{2}{*}{ PREFERENCIA } & ORDEN DE PREFERENCIA & COSTA RICA & EL SALVADOR & HONDURAS & NICARAGUA \\
\hline \multirow{2}{*}{ PRIMERA } & DEFENSA DEL TERRITORIO & 9,6 & 82,6 & 25,4 & 31,7 \\
& AYUDAR A POLIĆ́A & 23,1 & 2,2 & 11,9 & 26,8 \\
& DEFENDER CONSTITUCIÓN & 25,0 & 4,3 & 32,8 & 34,1 \\
& DESARROLLO NACIONAL & 17,3 & 4,3 & 19,4 & 4,9 \\
& COMBATIR NARCOTRÁFICO & 11,5 & 6,5 & 9,0 & 0,0 \\
& PACIFICAC. INTERNACIONAL & 5,8 & 0,0 & 1,5 & 2,4 \\
& NC & 7,7 & 0,0 & 0,0 & 0,0 \\
& NS & 0,0 & 0,0 & 0,0 & 0,0 \\
\hline \multirow{2}{*}{ SEGUNDA } & DEFENSA DEL TERRITORIO & 7,7 & 0,0 & 4,5 & 7,3 \\
& AYUDAR A POLICÍA & 15,4 & 17,4 & 19,4 & 22,0 \\
& DEFENDER CONSTITUCIÓN & 5,8 & 13,8 & 16,4 & 29,3 \\
& DESARROLLO NACIONAL & 19,2 & 15,2 & 22,4 & 29,3 \\
& COMBATIR NARCOTRÁFICO & 25,0 & 6,5 & 28,4 & 2,4 \\
& PACIFICAC. INTERNACIONAL & 13,5 & 39,1 & 7,5 & 7,3 \\
& NC & 13,5 & 8,7 & 1,5 & 2,4 \\
& NS & 0,0 & 0,0 & 0,0 & 0,0 \\
\hline
\end{tabular}

defensa de la Constitución. Mientras que el Salvador se decanta por la defensa del territorio nacional de una agresión extranjera $(82,6 \%)$. La segunda 'tarea' más importante que les es asignada según los hondureños y costarricenses, es combatir el narcotráfico, mientras que para El Salvador refiere a contribuir a procesos de pacificación internacional y Nicaragua apuesta porque tengan un papel más activo en el desarrollo nacional.

\section{Gráfico 15}

\section{Centroamérica: Funciones de las Fuerzas Armadas en el siglo XXI (primera opción)}

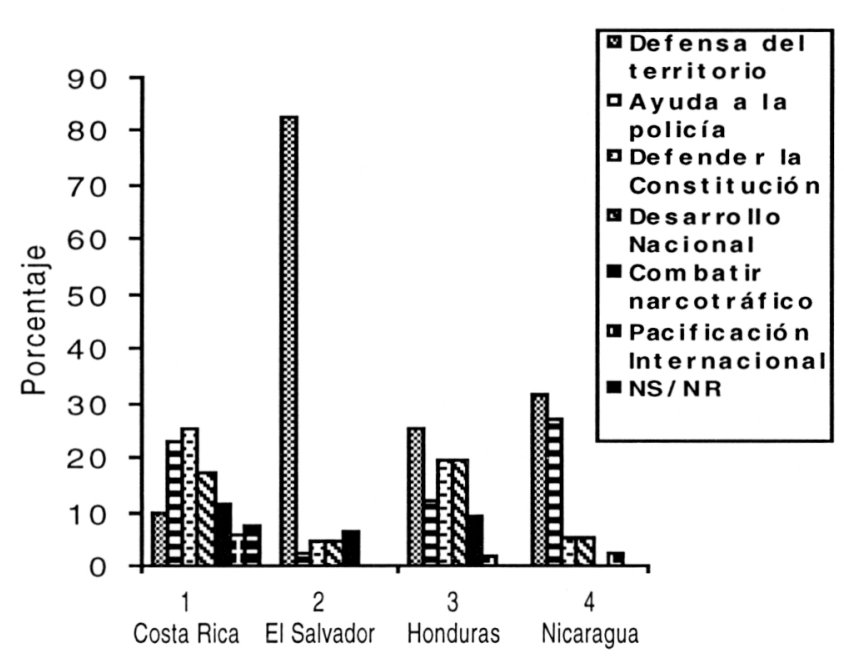

La cuestión pendiente de resolución, sigue siendo precisamente la definición de los ámbitos civiles y militares de gestión gubernamental. Las relaciones fuerzas armadas y gobierno son percibidas como un riesgo para la mayoría de los parlamentarios centroamericanos, en función del objetivo de la consolidación de la democracia en estos países. En El Salvador, Honduras y Nicaragua superan el $80 \%, 70 \%$ y $60 \%$, respectivamente, quienes consideran que constituyen mediana o mucha amenza. A ello se une el hecho de que ésta es una de las cuestiones en las que los parlamentarios rehusan responder. Tal es el caso de Nicaragua donde de casi una cuarta parte de los entrevistados no se obtuvo su opinión al respecto. Estos aspectos parecen evidenciar una dificultad para identificar el peso específico que se les asigna a los distintos actores políticos en el juego de poder y que aún se están definiendo las nuevas relaciones de fuerzas que caracterizan sus sistemas políticos.

\section{Gráfico 16}

\section{Centroamérica: Funciones de las Fuerzas Armadas en el siglo XXI (segunda opción)}

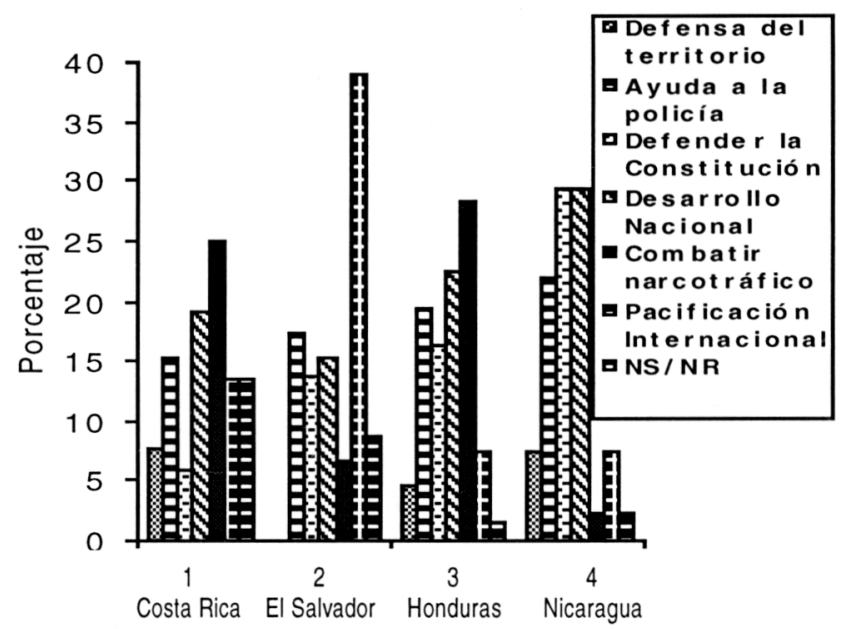

En todo caso lo que si es posible observar es la valoración respecto del nivel de la actividad política que despliegan las fuerzas armadas en estos países. A diferencia de El Salvador y Honduras, Nicaragua y Costa Rica coinciden en afirmar que la actividad política desplegada por las fuerzas armadas no es muy elevada en los últimos años (Ver Tabla n. ${ }^{\circ} 7$ ). En este punto, es importante destacar que los criterios de los parlamentarios de cada uno de los países debe ubicarse desde el contexto del desarrollo de sus estamentos de seguridad. Con la finalización de la guerra en Nicaragua la actividad de las 
fuerzas armadas se ha redefinido sustantivamente en el contexto de la transición democrática y del gobierno civil electo popularmente. Esta redefinición de su actividad, que es percibida como un repliegue en sus cuarteles y una dinámica de capacitación y desarrollo empresarial, es calificada de baja en relación al despliegue que implicaba el contexto de la guerra civil primero y la guerra de baja intensidad después. El caso de Costa Rica es distinto y corresponde al papel específico de sus fuerzas policiales cuya supeditación al Ministerio de Seguridad Pública les confiere una función técnica y administrativa que no se ha percibido ni antes ni ahora como una actividad política de amplio alcance?

\section{Gráfico 1}

Centroamérica: Relación Fuerzas Armadas-Gobierno como amenaza o riesgo para la consolidación democrática

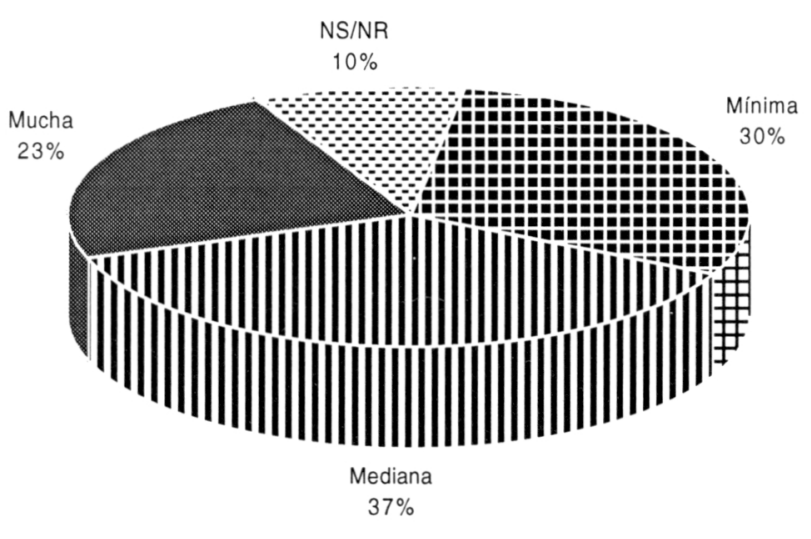

Gráfico 20

Centroamérica: Nivel de actividad política de las Fuerzas Armadas y Policiales

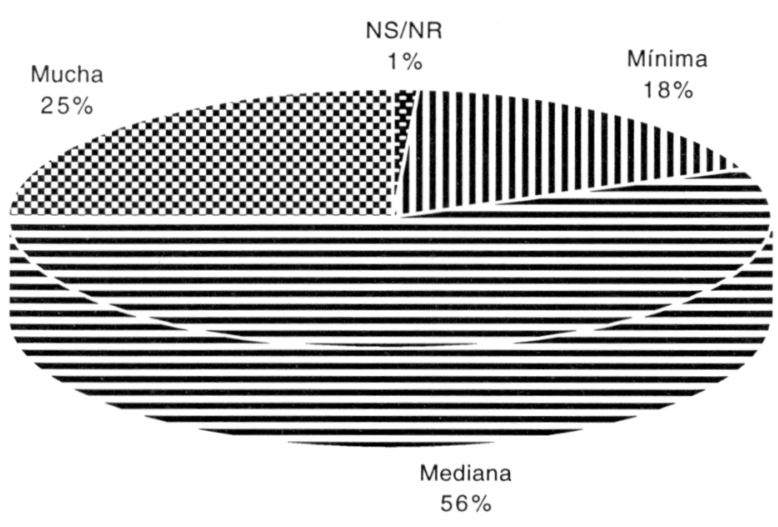

\section{LOS PARLAMENTARIOS Y LOS GRUPOS DE INTERÉS}

Las otras organizaciones sociales con las cuales también interactúan los parlamentarios resultan también un punto de referencia para identificar sus percpeciones respecto de los roles desempeñados por los demás actores en la dinámica política de sus países. Parece haber consenso en los diputados de la región, que los partidos políticos constituyen la organización más activa en todos los países. En sentido inverso se pronuncian los parlamentarios respecto de la actividad de las organizaciones sindicales. En Costa Rica, Nicaragua y El Salvador se considera mayoritariamente que su actividad es más bien baja, mientras que en Honduras las opiniones de los parlamentarios están divididas por la mitad respecto a la mayor o menor actividad de los sindicatos en su país

Gráfico 17

Centroamérica: Nivel de actividad de los Partidos Políticos

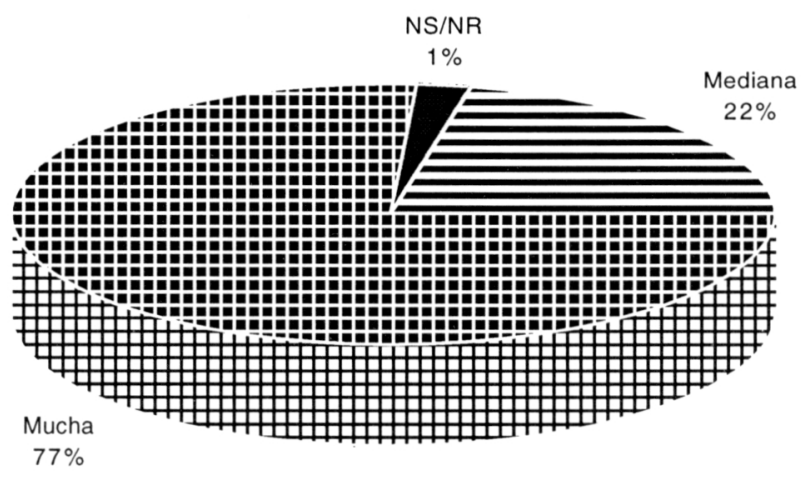

Gráfico 18

Centroamérica: Nivel de actividad política de los Sindicatos

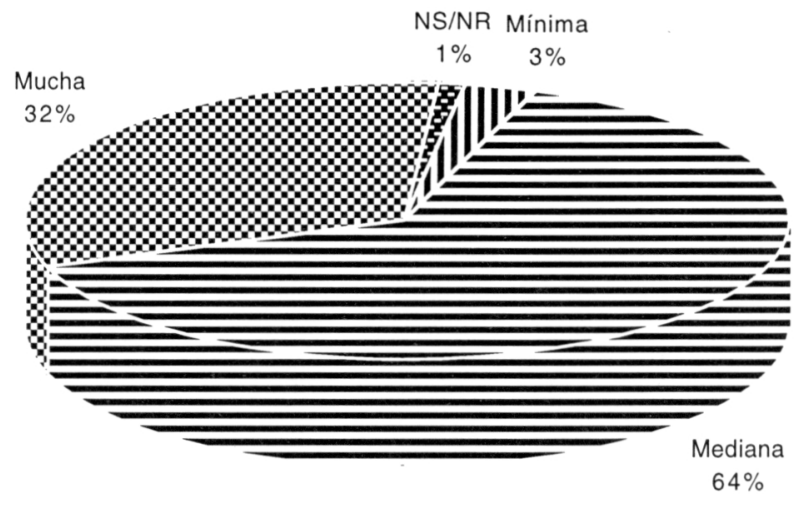

La actividad desplegada por los empresarios en los distintos países tiene distintas valoraciones por parte de los legisladores entrevistados. En y las opiniones se dividen por partes iguales respecto de una alta y una baja actividad

9. El nivel de actividad política de las fuerzas armadas, partidos políticos y grupos de interés, según la perciben los parlamentarios, ha sido agregada de la siguiente manera, en relación a los rangos establecidos en la encuesta original: poca $=$ mínima; alguna +regular $=$ mediana; bastante + muy importante $=$ mucha; $\mathrm{NC}+\mathrm{NS}=\mathrm{NS} / \mathrm{NR}$ 
TABLA N ${ }^{\circ} 7$ : PERCEPCIÓN DE ACTIVIDAD POLÍTICA DE OTROS ACTORES SOCIALES

\begin{tabular}{|c|c|c|c|c|c|}
\hline ACTORES & $\begin{array}{l}\text { RANGO DE } \\
\text { ACTIVIDAD }\end{array}$ & COSTA RICA & EL SALVADOR & HONDURAS & NICARAGUA \\
\hline PARTIDOS POLÍTICOS & $\begin{array}{l}\text { POCA } \\
\text { ALGUNA } \\
\text { REGULAR } \\
\text { BASTANTE } \\
\text { MUY } \\
\text { NC } \\
\text { NS }\end{array}$ & $\begin{array}{r}0,0 \% \\
3,8 \% \\
25,0 \% \\
26,9 \% \\
44,2 \% \\
0,0 \% \\
0,0 \%\end{array}$ & $\begin{array}{r}0,0 \% \\
8,7 \% \\
15,2 \% \\
28,3 \% \\
47,8 \% \\
0,0 \% \\
0,0 \%\end{array}$ & $\begin{array}{r}0,0 \% \\
0,0 \% \\
9,0 \% \\
14,9 \% \\
73,1 \% \\
0,0 \% \\
3,0 \%\end{array}$ & $\begin{array}{r}0,0 \% \\
7,3 \% \\
19,5 \% \\
46,3 \% \\
26,8 \% \\
0,0 \% \\
0,0 \%\end{array}$ \\
\hline SINDICATOS & $\begin{array}{l}\text { POCA } \\
\text { ALGUNA } \\
\text { REGULAR } \\
\text { BASTANTE } \\
\text { MUY } \\
\text { NC } \\
\text { NS }\end{array}$ & $\begin{array}{r}0,0 \% \\
48,1 \% \\
38,5 \% \\
13,5 \% \\
0,0 \% \\
0,0 \% \\
0,0 \%\end{array}$ & $\begin{array}{r}4,3 \% \\
17,4 \% \\
39,1 \% \\
21,7 \% \\
17,4 \% \\
0,0 \% \\
0,0 \%\end{array}$ & $\begin{array}{r}4,5 \% \\
10,4 \% \\
23,9 \% \\
23,9 \% \\
34,3 \% \\
0,0 \% \\
3,0 \%\end{array}$ & $\begin{array}{r}2,4 \% \\
34,1 \% \\
46,3 \% \\
17,1 \% \\
0,0 \% \\
0,0 \% \\
0,0 \%\end{array}$ \\
\hline EMPRESARIOS & $\begin{array}{l}\text { POCA } \\
\text { ALGUNA } \\
\text { REGULAR } \\
\text { BASTANTE } \\
\text { MUY } \\
\text { NC } \\
\text { NS }\end{array}$ & $\begin{array}{r}3,8 \% \\
9,6 \% \\
36,5 \% \\
38,5 \% \\
11,5 \% \\
0,0 \% \\
0,0 \%\end{array}$ & $\begin{array}{r}0,0 \% \\
17,4 \% \\
34,8 \% \\
28,3 \% \\
19,6 \% \\
0,0 \% \\
0,0 \%\end{array}$ & $\begin{array}{r}1,5 \% \\
6,0 \% \\
20,9 \% \\
37,3 \% \\
31,3 \% \\
0,0 \% \\
3,0 \%\end{array}$ & $\begin{array}{r}2,4 \% \\
41,5 \% \\
46,3 \% \\
9,8 \% \\
0,0 \% \\
0,0 \% \\
0,0 \%\end{array}$ \\
\hline $\begin{array}{l}\text { FUERZAS ARMADAS } \\
\text { Y POLICIALES }\end{array}$ & $\begin{array}{l}\text { POCA } \\
\text { ALGUNA } \\
\text { REGULAR } \\
\text { BASTANTE } \\
\text { MUY } \\
\text { NC } \\
\text { NS }\end{array}$ & $\begin{array}{r}44,2 \% \\
26,9 \% \\
19,2 \% \\
9,6 \% \\
0,0 \% \\
0,0 \% \\
0,0 \%\end{array}$ & $\begin{array}{r}10,9 \% \\
17,4 \% \\
41,3 \% \\
15,2 \% \\
15,2 \% \\
0,0 \% \\
0,0 \%\end{array}$ & $\begin{array}{r}9,0 \% \\
9,0 \% \\
32,8 \% \\
32,8 \% \\
13,4 \% \\
0,0 \% \\
3,0 \%\end{array}$ & $\begin{array}{r}7,3 \% \\
48,8 \% \\
29,3 \% \\
12,2 \% \\
0,0 \% \\
2,4 \% \\
0,0 \%\end{array}$ \\
\hline IGLESIA CATÓLICA & $\begin{array}{l}\text { POCA } \\
\text { ALGUNA } \\
\text { REGULAR } \\
\text { BASTANTE } \\
\text { MUY } \\
\text { NC } \\
\text { NS }\end{array}$ & $\begin{array}{r}5,8 \% \\
7,7 \% \\
30,8 \% \\
46,2 \% \\
7,7 \% \\
1,9 \% \\
0,0 \%\end{array}$ & $\begin{array}{r}4,3 \% \\
10,9 \% \\
37,0 \% \\
34,8 \% \\
13,0 \% \\
0,0 \% \\
0,0 \%\end{array}$ & $\begin{array}{r}4,5 \% \\
10,4 \% \\
25,4 \% \\
29,9 \% \\
26,9 \% \\
0,0 \% \\
3,0 \%\end{array}$ & $\begin{array}{r}4,9 \% \\
24,4 \% \\
41,5 \% \\
7,3 \% \\
22,0 \% \\
0,0 \% \\
0,0 \%\end{array}$ \\
\hline OTRAS IGLESIAS & $\begin{array}{l}\text { POCA } \\
\text { ALGUNA } \\
\text { REGULAR } \\
\text { BASTANTE } \\
\text { MUY } \\
\text { NC } \\
\text { NS }\end{array}$ & $\begin{array}{r}25,9 \% \\
44,2 \% \\
19,2 \% \\
5,8 \% \\
3,8 \% \\
0,0 \% \\
1,9 \%\end{array}$ & $\begin{array}{r}10,9 \% \\
47,8 \% \\
17,4 \% \\
15,2 \% \\
8,7 \% \\
0,0 \% \\
0,0 \%\end{array}$ & $\begin{array}{r}19,4 \% \\
23,9 \% \\
34,3 \% \\
10,4 \% \\
9,0 \% \\
0,0 \% \\
3,0 \%\end{array}$ & $\begin{array}{r}7,3 \% \\
24,4 \% \\
41,5 \% \\
7,3 \% \\
17,1 \% \\
0,0 \% \\
2,4 \%\end{array}$ \\
\hline
\end{tabular}

de los empresarios organizados. En Honduras, El Salvador y Costa Rica, hay una valoración que resalta una importante actividad del sector empresarial mientras que en Nicaragua no se considera su actividad como muy elevada en la dinámica política nacional.

Las opiniones sobre la actividad de Iglesia Católica se debaten en los alrededores del 50\% respecto de su mucha o poca actividad en Costa Rica, El Salvador y Honduras. En Nicaragua la opinión mayoritaria es que es más bien poco activa. Es con referencia a las otras iglesias que todos coinciden en afirmar que su actividad es mayoritariamente baja en cada uno de los países.

\section{Gráfico 19}

Centroamérica: Nivel de actividad política de los grupos empresarilas NS/NR Minima

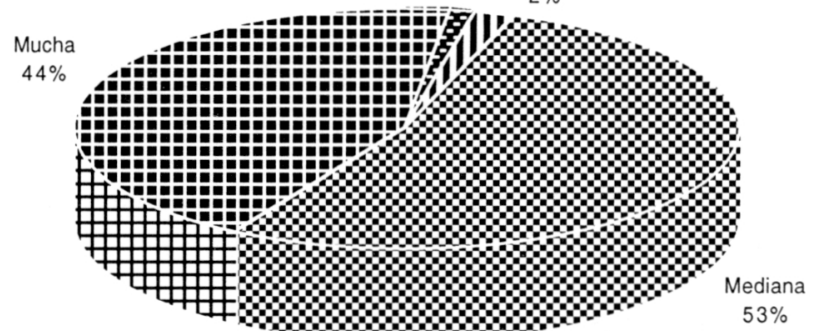


Gráfico 22

Centroamérica: Nivel de actividad política de otras iglesias

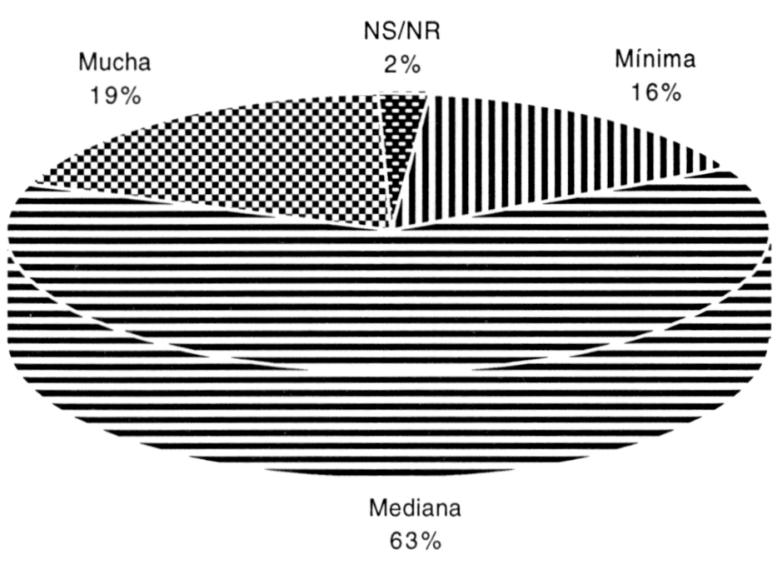

La importancia de estas percepciones radica en los contactos, las presiones y demandas de que son objeto los parlamentarios. Las propuestas y programas, proyectos y mociones, le son sugeridas por los grupos de interés que los parlamentarios consideran más activos. Es importante hacer notar que en la generalidad de los entrevistados se hizo manifiesto el interés por crear mecanismos que incentiven a las organizaciones de la sociedad civil a una participación más activa y, consecuentemente, a una mayor colaboración en su gestión parlamentaria.

\section{CONSIDERACIONES FINALES}

Para comprender plenamente el papel que están desempeñando los parlamentarios centroamericanos, es particularmente necesario distinguir las condiciones que determinan su gestión política como representantes de los pueblos. Las condiciones de estabilidad/inestabilidad marcadas por la transición que viven la mayor parte de los centroamericanos, ponen un techo al quehacer político de los parlamentarios desde el cual perciben sus relaciones con las demás instituciones políticas. Estas, a su vez, se encuentran experimentando procesos de transformación únicos en su historia: las Fuerzas Armadas, los desmovilizados, las instituciones de los otros poderes del Estado, los grupos de intereses articulados por demandas de género, étnicas y culturales, etc. Así, el peso de la inmediatez, mantiene una dinámica de enorme tensión en la que el objetivo es nada menos que construir todo un marco jurídico e institucional que dé espacio de acción a los actores políticos que han saltado a la escena pública. Pero están también las exigencias no menores ni menos complejas de la reducción del déficit, del cumplimiento de compromisos con las entidades financieras internacionales, que llevan invariablemente a negociar nuevos empréstitos y aplicar políticas impositivas e impopulares, sobretodo en el contexto de la pobreza que caracteriza los países centroamericanos.
En este contexto, las percepciones de los demás actores políticos por parte de los parlamentarios, resulta de especial interés porque recupera uno de los principales signos de la transición y es el paso al reconocimiento de los 'otros' como interlocutores válidos, legítimos. Es un juego de poder que se expresa en escenarios cambiantes y diversos y que los diputados de la región están descubriendo y/o redescubriendo.

Es interesante observar que el ejercicio de visualizar el papel del Ejecutivo a través del papel y el rol que le confieren al Estado en su conjunto, es a la vez una báscula para pesar sus propias capacidades como institución estatal que constituye a la vez el eje de conformación de los Estados democráticos al constituirse en la instancia de la triple dimensión de representación, control político y legislación.

En todo caso, sigue siendo tarea pendiente el identificar las formas concretas de ejercicio y gestión pública, de acuerdo a las competencias que las constituciones les confieren sobre todo al Ejecutivo y a las Fuerzas Armadas. Hay que recordar que el principal reto que las constituciones se plantearon fue precisamente el traspaso del poder político de los militares a los civiles, sin embargo está claro que ese traspaso consagrado constitucionalmente, es en la práctica política un reclamo de espacios y legitimidad ante la opinión pública por parte de de los diferentes actores. Es un proceso que está lejos de acabar con la aprobación del pacto social esbozado en las Asambleas Constituyentes. Por eso son escuetas en lo que refiere a diversas funciones que de estas instituciones tienen expectativas los parlamentarios, como se ha podido ver a través de la encuesta, base de este artículo. Lo que si varía sustancialmente en el marco constitucional, es la apertura hacia organizaciones sociales del más diverso tipo, las que, a juicio de los parlamentarios, han encontrado eco fundamentalmente en los partidos políticos, en lo que refiere a su actividad política y al ejercicio de influencias efectivas en su gestión parlamentaria. Al parecer, las otras organizaciones sociales aún no están ejerciendo toda la presión y fuerza que de ellas mismas esperan los parlamentarios, a fin de conocer no sólo sus demandas, sino su colaboración en la definición de políticas en el difícil arte de la toma de deciones pública en condiciones de extrema escasez.

En resumen, que el reconocimiento mutuo de los actores políticos de las democracias centroamericanas, sobretodo en el caso de las más recientes aquí observadas, es todavía un proceso lento, en el cual pareciera encontrarse una especie de círculo vicioso: aumenta la confianza si hay una efectiva gestión pública y ésta sólo es posible si se cuenta con la confianza y la colaboración entre poderes del Estado y entre estos y las organizaciones sociales. Por eso puede decirse que uno de los grandes retos para la consolidación democrática de la región es, en efecto, construir relaciones, o reconstruirlas. Dar a conocer cómo se perciben unos a otros, puede ser un aporte en esa dirección. 


\section{BIBLIOGRAFÍA}

AlCÁNTARA, Manuel y CRESPO, Ismael (eds.). Los limites de la consolidación democrática en América Latina. Ediciones Universidad de Salamanca. Salamanca, 1995.

Chacón, Alexander; ChavarríA, Alexander y McGowan, Kathleen (coord.). La Asamblea Legislativa de Costa Rica y sus Diputados: periodo 1994-1998. Asamblea Legislativa-Centro para la Democracia. San José, 1995.

CAPEL. Legislación electoral comparada: Colombia, México, Panamá, Venezuela y Centroamérica. Ediciones CAPEL. San José, 1986.

FLACSO. Centroamérica en cifras: 1980-1992. FLACSOPrograma Costa Rica. San José, 1995.

- Centro América entre democracia y desorganización. FLACSO-Programa Guatemala. Guatemala, 1994.

- Historia General de Centroamérica. Tomo VI. Segunda edición. FLACSO-Programa Costa Rica. San José, 1994.

- Transición a la democracia y reforma del Estado en México. Barros, José; Javier Hurtado y German Pérez (compiladores). FLACSO-Sede México. México, 1991.

Kelman, Steven. La política pública en el Estado moderno. Grupo Editor Latinomaericano. Buenos Aires, 1992.

LIJPHART, Arend. Las democracias contemporáneas. Editorial Ariel. Barcelona, 1987.
O’Donnell, Guillermo; Phillippe, C. Schmitter y LAURENCE Whitehead (compiladores). Transiciones desde un gobierno autoritario. Tomos 3 y 4 . Paidós. Buenos Aires, 1988.

Mendoza Mora, Arnoldo de Jesús. Gobierno, Empresarios $y$ sindicatos en torno al 'Fomento del sindicalismo'. Tesis de Maestría en Sociología. Universidad de Costa Rica, 1994.

Parry Geraint. Political Elites. Seventh impression. George Allen \& Unwin Ltd. London, 1986.

PRZEWORSKI, Adam. Democracy and the market. Cambridge University Press. Reprinted (twice). U.S.A., 1993.

ROHRSCHNEIDER, Robert. "Report from the Laboratory: The Influence of Institutions on Political Elites' Democratic Values in Germany". In American Political Science Review. Vol. 88. n. ${ }^{\circ}$ 4. December 1994.

Ramírez Altamirano, Marina. Manual de procedimientos legislativos. IJSA. San José, 1994.

Rojas Bolaños, Manuel y otros. Costa Rica: la democracia inconclusa. IIS-DEI. San José, 1989.

Sullivan, Mark P. "Central America: Background on the Region's Legislatures”. In CRS Report for Congress. Congressional Research Service. The Library of Congress. Updated December 5. USA, 1994.

Urcuyo, Constantino. Más democracia. Ediciones Sanabria. San José, 1992.

\section{RESUMEN}

El presente artículo analiza las percepciones de los parlamentarios de cuatro países de Centroamérica (Costa Rica, El Salvador, Honduras y Nicaragua), respecto del rol que ejercen las instituciones políticas de esos países en la construcción y consolidación de sistemas políticos democráticos. En un contexto de redefinición de los actores sociales en una región que ha optado recientemente por la resolución pacífica de los conflictos y la aplicación de las reglas del juego democrático, resulta especialmente sugerente identificar el reconocimiento mutuo de los actores políticos relevantes, como "interlocutores válidos". La discusión sobre este reconocimiento mutuo, es vital para avanzar en la búsqueda conjunta de alternativas para enfrentar la pobreza, las debilidades institucionales y jurídicas, la reestructuración de los ejércitos, el fortalecimiento del poder civil y la exclusión social y política; que son algunos de los grandes retos que se plantean los centroamericanos frente al fantasma de la reversibilidad del proceso de pacificación y democratización que ha sido sin duda el principal proyecto político regional del siglo XX.

\section{ABSTRACT}

This article analyzes the perceptions of parliamentary members in four Central American countries (Costa Rica, El Salvador, Honduras, and Nicaragua), in regard to the role exercised by political institutions in building and consolidating democratic political systems, in those countries. In a context in which social actors have been redefined, within a region that has recently chosen pacific settlement of conflicts mechanisms and the application of democratic rules of the geme, it is especially interesting to identify how the main political actors have recognezed each other as "valid speakers". The discussion about this mutual reconaissance is vital to advance in the search for joint alternatives to challenge poverty, the institutional and judiciary weaknesses, to reestructure the military, the strenghthening of civilian power, and the political and social exclusive processes. These are some of the main challenges posed by Central Americans, which face the ghost of reversing the process of democratization and pacification, which has been, without a doubt, the main regional political project in the twentieth century. 